\title{
The Seasonality of the Great Plains Low-Level Jet and ENSO Relationship
}

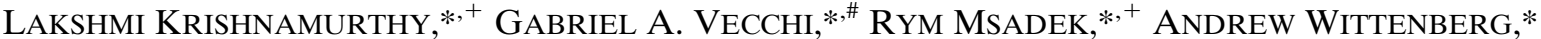 \\ THOMAS L. DELWORTH, ,* AND FANRONG ZENG* \\ * National Oceanic and Atmospheric Administration/Geophysical Fluid Dynamics Laboratory, Princeton, New Jersey \\ ${ }^{+}$University Corporation for Atmospheric Research, Boulder, Colorado \\ \# Atmospheric and Oceanic Sciences Program, Princeton University, Princeton, New Jersey
}

(Manuscript received 22 August 2014, in final form 2 March 2015)

\begin{abstract}
This study investigates the seasonality of the relationship between the Great Plains low-level jet (GPLLJ) and the Pacific Ocean from spring to summer, using observational analysis and coupled model experiments. The observed GPLLJ and El Niño-Southern Oscillation (ENSO) relation undergoes seasonal changes with a stronger GPLLJ associated with La Niña in boreal spring and El Niño in boreal summer. The ability of the GFDL Forecast-Oriented Low Ocean Resolution (FLOR) global coupled climate model, which has the highresolution atmospheric and land components, to simulate the observed seasonality in the GPLLJ-ENSO relationship is assessed. The importance of simulating the magnitude and phase locking of ENSO accurately in order to better simulate its seasonal teleconnections with the Intra-Americas Sea (IAS) is demonstrated. This study explores the mechanisms for seasonal changes in the GPLLJ-ENSO relation in model and observations. It is hypothesized that ENSO affects the GPLLJ variability through the Caribbean low-level jet (CLLJ) during the summer and spring seasons. These results suggest that climate models with improved ENSO variability would advance our ability to simulate and predict seasonal variations of the GPLLJ and their associated impacts on the United States.
\end{abstract}

\section{Introduction}

The Caribbean and Great Plains low-level jets of the Intra-Americas Sea (IAS) serve as an important source of moisture for the adjacent land and oceanic regions. The Caribbean low-level jet (CLLJ) transports moisture from the tropical Atlantic into the IAS, which is further transported over to the continental United States by the Great Plains low-level jet (GPLLJ), together referred to as the IAS LLJ (Munoz and Enfield 2011). The GPLLJ acts as a crucial conduit of moisture from the tropical Atlantic to the continental United States. It serves as an important source of rainfall over the agricultural land in the Great Plains (Stensrud 1996) and it further influences tornadoes over the United States, by changing the vertical shear and moisture availability (Lee et al. 2013; Munoz and Enfield 2011). The strength, location,

Corresponding author address: Lakshmi Krishnamurthy, UCAR NOAA/Geophysical Fluid Dynamics Laboratory, Princeton University Forrestal Campus, 201 Forrestal Road, Princeton, NJ 08540-6649.

E-mail: lakshmi.krishnamurthy@noaa.gov and seasonal timing of the GPLLJ have also been shown to have a profound influence on the regional hydroclimate of the central United States (Weaver and Nigam 2008; Weaver et al. 2009). In addition, on a seasonal basis, the GPLLJ has societal impacts on forestry and human health through its effect on seed dispersion, assisting the migration of birds and insects, which would further contribute to the influx of pests and disease causing agents (Stensrud 1996). Therefore, there is robust scientific as well as socioeconomic motivation to understand the factors that control the variations of the GPLLJ.

Climatologically, the GPLLJ is characterized by a maximum in the meridional wind at around $925 \mathrm{hPa}$, with a peak amplitude in the region between $25^{\circ}-35^{\circ} \mathrm{N}$ and $102^{\circ}-97^{\circ} \mathrm{W}$, which encompasses Oklahoma, Texas, and Mexico. A GPLLJ index based on the areaaveraged meridional wind in this region was suggested by Weaver and Nigam (2008), which was designed to include the maximum amplitudes of the climatological meridional wind and moisture flux. Generally, a stronger GPLLJ increases the probability of drought conditions at the entrance region and flood conditions at the 


\section{Observations}

(a) AMJ V925 and AMJ GPLLJ

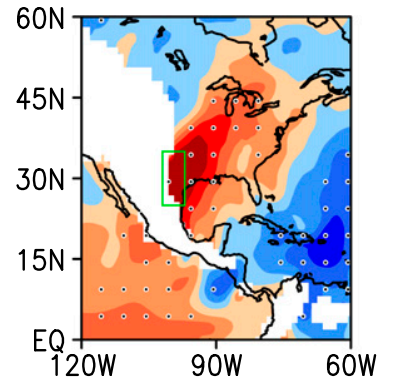

(b) JAS V925 and JAS GPLLJ

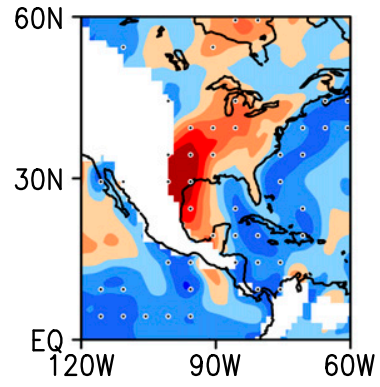

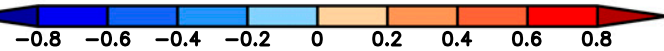

(c) AMJ SST and AMJ GPLLJ

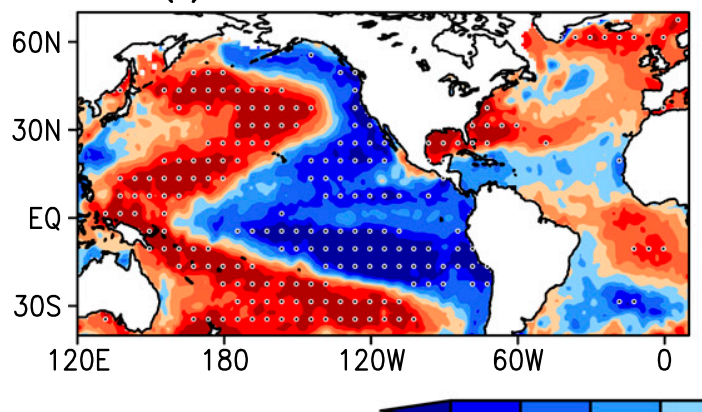

(d) JAS SST and JAS GPLLJ

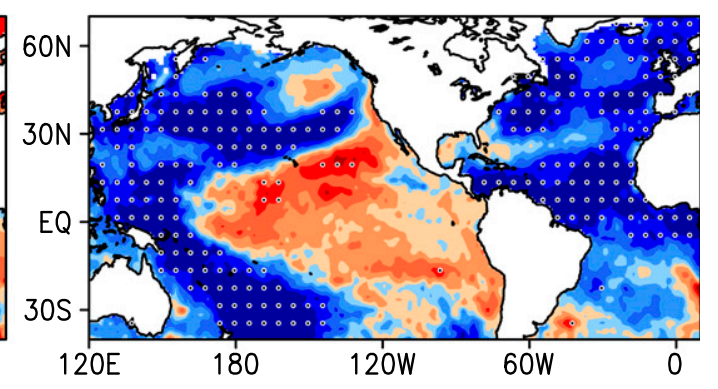

FIG. 1. Point correlation between seasonal anomalies of MERRA meridional winds at $925 \mathrm{hPa}$ and the GPLLJ for (a) AMJ and (b) JAS for the period 1979-2013. Point correlation between seasonal anomalies of HadISST and GPLLJ for (c) AMJ and (d) JAS for the period 1979-2013. The dotted regions indicate 5\% significance level. The green box represents the area $25^{\circ}-35^{\circ} \mathrm{N}, 102^{\circ}-97^{\circ} \mathrm{W}$ over which GPLLJ index is defined.

exit region, by leading to above-normal rainfall over the central United States (Oklahoma, Kansas, South Dakota, Nebraska, Arkansas, Missouri, Iowa, and Minnesota) and below-normal rainfall over the southeastern United States (Texas, Louisiana, Mississippi, Alabama, Georgia, South Carolina, and Florida) and the Gulf of Mexico (Weaver et al. 2009). The GPLLJ exhibits a distinct annual cycle in observations, developing in April-June (AMJ), peaking in July, and decaying in August and September. Analysis of the models from phase 3 of the Coupled Model Intercomparison Project (CMIP3) suggests a strengthening of the GPLLJ by the end of the twenty-first century (Cook et al. 2008). It is important to determine the factors that control the changes in the GPLLJ and the ability of models to simulate these factors in order to improve the predictions of its strength and understand the associated impacts on the IAS and the North American climate.

The GPLLJ exhibits strong year-to-year variations, which are influenced by the sea surface temperature (SST) variations in the adjacent Pacific and Atlantic Oceans. Figure 1 shows anomalies of meridional wind at $925 \mathrm{hPa}$ and SST associated with an anomalously strong
GPLLJ during boreal spring and summer. A stronger GPLLJ manifests as anomalously strong southerlies over the Great Plains, to the east of the Rockies and west of the Mississippi River, during both spring and summer. The associated SST pattern shows a La Niñalike state in the tropical Pacific Ocean during spring and an El Niño-like state during summer. This suggests that the GPLLJ (with positive convention corresponding to stronger southerly winds) is negatively correlated with the El Niño-Southern Oscillation (ENSO) during spring and positively correlated during summer. ${ }^{1}$

This seasonality of the observed relationship between the GPLLJ and the equatorial Pacific surface temperatures serves to reconcile an apparent split in the published studies on the GPLLJ and ENSO relation, which tend to fall into two categories. The first group of papers suggests a negative correlation between the GPLLJ and

\footnotetext{
${ }^{1}$ We clarify that the spring and summer GPLLJ events associated with different states of ENSO are not the same events persisting from one season to the next (as the correlation between spring GPLLJ and summer GPLLJ is 0.04).
} 
ENSO (e.g., Munoz and Enfield 2011; Lee et al. 2013), and the second group (e.g., Weaver et al. 2009; Schubert et al. 2004; Ting and Wang 1997) hints toward a positive GPLLJ-ENSO correlation. It turns out that the set of papers finding a negative relation focused on the springtime GPLLJ, while the others looked at the boreal summer. Focusing on spring, an observational study by Munoz and Enfield (2011) suggests that the colder SSTs in the tropical Pacific favor a stronger IAS LLJ (IAS LLJ represents both the CLLJ and GPLLJ). Further, based on observational analysis and atmospheric model experiments, Lee et al. (2013) show that an increased moisture transport from the Gulf of Mexico to the United States in spring is associated with a positive trans-Niño (negative SSTs in the central Pacific and positive SSTs in a small region over the far eastern $\mathrm{Pa}$ cific, representing a transition state from La Niña to El Niño). This increased moisture transport from the Gulf of Mexico to the United States would imply a stronger GPLLJ. Lee et al. (2013) also argues that the large-scale atmospheric anomalies, such as enhanced moisture transport over to the central United States, are not seen when the SSTs in the central and eastern Pacific are of the same sign. This is in contrast to Fig. $1 \mathrm{~b}$ in which the SST anomalies associated with a stronger GPLLJ have the same sign in the eastern and central Pacific in spring. These differences may arise from the spatial shifts in the location of the GPLLJ and their relation to SST. The inplace strengthening of the GPLLJ [similar to the index used in this paper and mode 1 of Weaver et al. (2012) and Weaver (2013)] is related to the same sign of the SSTs in the eastern and central Pacific. The southeastward shift of the GPLLJ [mode 2 in Weaver et al. (2012, 2013)] is related to the opposite sign of the SSTs in the central and eastern Pacific.

Other studies emphasize the role of summer SSTs on the GPLLJ more than the spring SSTs (Weaver et al. 2009). A warm Pacific and cold Atlantic were shown to strengthen the summer GPLLJ and the associated Great Plains precipitation. Both the low-frequency and the interannual variability of the Pacific SSTs are known to drive the summer rainfall over the Great Plains with enhanced precipitation when the tropical Pacific SSTs are anomalously warm (Schubert et al. 2004). This is in agreement with Ting and Wang (1997), who concluded that the wet summers over the Great Plains are associated with above-normal SSTs over the eastern Pacific and below-normal SSTs over the central North Pacific.

This seasonality in the GPLLJ-ENSO relationship is peculiar and hence we seek here to understand (i) whether it is a statistical artifact (from a finite data sample) or a true seasonal change in the relationship; (ii) if it is not spurious, whether the current coupled climate models can capture the seasonal changes in the GPLLJENSO relation; and (iii) the mechanism that leads to such a seasonal change in the relation between the GPLLJ and ENSO. To pursue these goals, we explore the relation between the GPLLJ and the Pacific SSTs in a high-resolution global coupled model, using targeted perturbation experiments. The data, model, and model experiments are described in section 2. Results are presented in section 3. The mechanism for the GPLLJ-ENSO relation is proposed in section 4 and conclusions are provided in section 5 .

\section{Data and methods}

\section{a. Observations}

We explore observed sea level pressure (SLP), geopotential heights, and zonal and meridional winds at 17 vertical levels derived from the National Centers for Environmental Prediction-National Center for Atmospheric Research (NCEP-NCAR) reanalysis for the period 1948-2010 with a resolution of $2.5^{\circ} \times 2.5^{\circ}$ (Kalnay et al. 1996) as an observationally based constraint on the GPLLJ. We also make use of the highresolution National Aeronautics and Space Administration (NASA) Modern-Era Retrospective Analysis for Research and Applications (MERRA) sea level pressure, geopotential heights, and zonal and meridional winds for the period 1979-2013, on a $0.5^{\circ} \times 0.5^{\circ}$ spatial grid (Rienecker et al. 2011). The NCEP-NCAR reanalysis dataset is used in conjunction with MERRA as NCEP-NCAR spans a longer time period. In addition, we also compare with recent reanalysis products such as the NCEP Climate Forecast System Reanalysis (CFSR) and the European Centre for Medium-Range Weather Forecasts (ECMWF) interim reanalysis (ERA-Interim). CFSR (Saha et al. 2010) is available at a horizontal resolution of $0.5^{\circ} \times 0.5^{\circ}$ for the period 1979 2009. ERA-Interim (Dee et al. 2011) is on $1.5^{\circ} \times 1.5^{\circ}$ grid for the period of 1979-2013.

The SST data obtained from the Hadley Centre Sea Ice and Sea Surface Temperature dataset, version 1.1 (HadISST1.1; Rayner et al. 2003), is explored. The SST data are available over the 1870-2013 period and on a $1^{\circ} \times 1^{\circ}$ spatial grid. Hereafter, the term "observations" is used for reanalysis interchangeably, acknowledging that reanalyses are not observations but observationally constrained estimates.

\section{b. Global coupled model}

In this paper, we use the newly developed Geophysical Fluid Dynamics Laboratory (GFDL) ForecastOriented Low Ocean Resolution (FLOR) model. This 
model drives from the GFDL Coupled Model, version 2.5 (CM2.5; Delworth et al. 2012). It has a highresolution atmospheric component at $50 \mathrm{~km}$ with 17 vertical levels and a low-resolution oceanic component at $1^{\circ}$. A detailed description of FLOR can be found in Jia et al. (2015) and Vecchi et al. (2014). We use $600 \mathrm{yr}$ of a FLOR 1990 control run for analysis and subsequent model experiments. We compare FLOR with an earlier version of the GFDL model, CM2.1, in the model validation section. CM2.1 has a resolution of $2^{\circ}$ in the atmosphere and $1^{\circ}$ in the ocean and is thoroughly described in Delworth et al. (2006). We also use a fluxadjusted version of FLOR (FLOR-FA), which is run for $500 \mathrm{yr}$. The correction of fluxes in this model has the effect of largely reducing the SST bias, which affects the model's intrinsic variability (Vecchi et al. 2014). The implementation of the flux adjustment in FLOR is described in Vecchi et al. (2014).

As unadjusted FLOR has biases in the mean state and variability relative to the observations and to FLORFA, we design a coupled model experiment using FLOR. Further details on the motivation to perform this experiment will be discussed in section 3 . In this model experiment (referred to as FLOR-FA_ENSO), the tropical Pacific SSTs are restored to the FLOR monthly climatology (repeating every year) plus the interannually varying FLOR-FA monthly anomalies based on years $101-200$ of the control integration. The restoring is done with a 5-day time scale. The rest of the oceanic domain is fully coupled. In other words, the atmospheric model feels the restored SSTs in the tropical Pacific, and the SSTs generated by the FLOR ocean model in the other oceanic basins. We have also included a $10^{\circ}$ latitudelongitude buffer zone for a smoother transition between the restored and the fully coupled regions, in which the strength of restoring decreases linearly from $1 / 5$ to zero day. The initial conditions for FLOR-FA_ ENSO are derived from the long control simulation of FLOR.

We also perform a second perturbation experiment using FLOR-FA, where the tropical Pacific SSTs are restored to the monthly climatological SSTs from the FLOR-FA simulation. This experiment was performed to understand the variability of the IAS climate in the absence of ENSO. This experimental run, where the ENSO variability is suppressed, is referred to as FLORFA-no_ENSO. The two perturbation experiments described above are run for 100 model years.

\section{c. Method of analysis}

In this study, we apply correlation and composite analysis to characterize the conditions associated with enhanced/suppressed GPLLJ strength. We have applied a Student's $t$ test to assess the significance of correlations and composites. In addition to this, we have also applied field significance test (von Storch and Zwiers 1999) for spatial correlations between GPLLJ and SST anomalies based on the model data. For FLOR, the number of grid points significant at $95 \%$ level is 31917 and 26851 for spring and summer, respectively. For FLOR-FA, the number of grid points significant at $95 \%$ level is 30234 and 16501 for spring and summer, respectively.

\section{Results}

\section{a. Simulation of the GPLLJ-ENSO relation in FLOR}

The recent observations suggest that the relationship between meridional winds over the Great Plains and the tropical Pacific SSTs changes with seasons (Fig. 1). Given the limited observational sample size, it is possible that this peculiar seasonal transition in the GPLLJENSO relation is due to sampling. Therefore, we use the 600-yr-long control simulation of FLOR to test if this model is able to recover this change. First, we test the ability of the model to capture the climatology and variability of the GPLLJ compared to reanalysis and its relation with the U.S. rainfall.

\section{1) Mean STAte AND VARIABILITy OF THE GPPLJ AND ITS RELATION TO THE U.S. RAINFALL}

The climatology of FLOR meridional winds at $925 \mathrm{hPa}$ (V925) is compared with reanalysis winds and CM2.1 for the AMJ and July-September (JAS) seasons (Fig. 2). The reanalysis suggest maximum climatological winds of about $4 \mathrm{~m} \mathrm{~s}^{-1}$ located between $20^{\circ}$ and $40^{\circ} \mathrm{N}$ and centered to the east of the Rockies. The structure of the GPLLJ is quite similar in AMJ and JAS. The FLOR model is able to capture the strength and structure of the GPLLJ during both spring and summer compared with reanalysis. Any improvements in the GPLLJ simulation over CM2.1 in capturing the longitudinal extent of the jet are modest.

The observed standard deviation of V925 for AMJ and JAS indicates that the maximum variability of the meridional winds is collocated in the region of the maximum climatological southerly winds (Fig. 3). The wind variability over the GPLLJ region is slightly stronger in spring than in summer. FLOR simulates this enhanced variability in spring relative to summer, but it underestimates the variability over the Gulf of Mexico and across the Yucatan Channel in spring and over the eastern tropical Pacific in summer, compared to CM2.1 and MERRA. This may be related to sampling as FLOR 
(a) MERRA

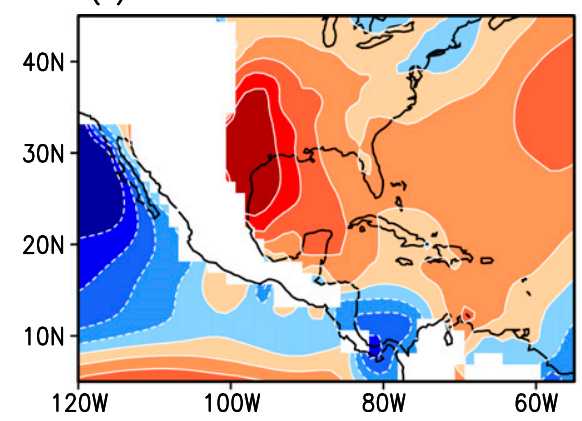

(c) $\mathrm{CM} 2.1$

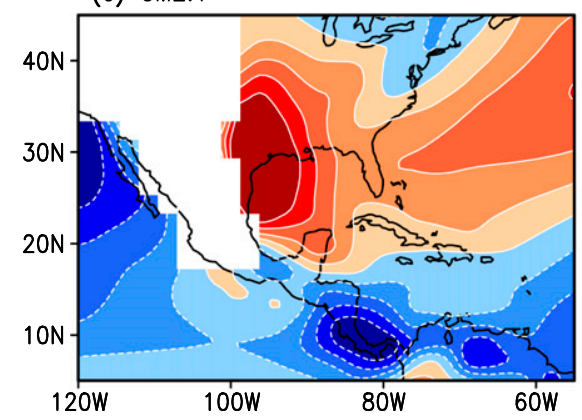

(e) FLOR

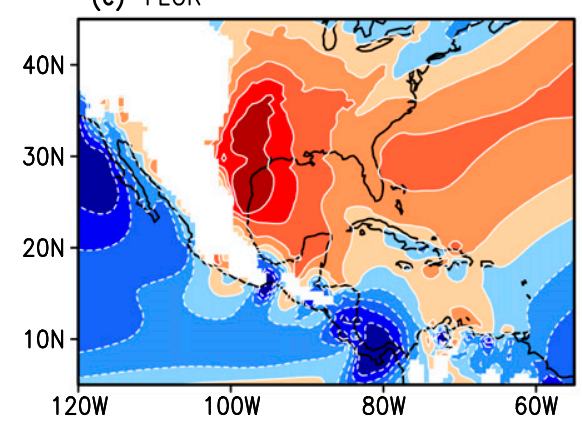

(b) MERRA

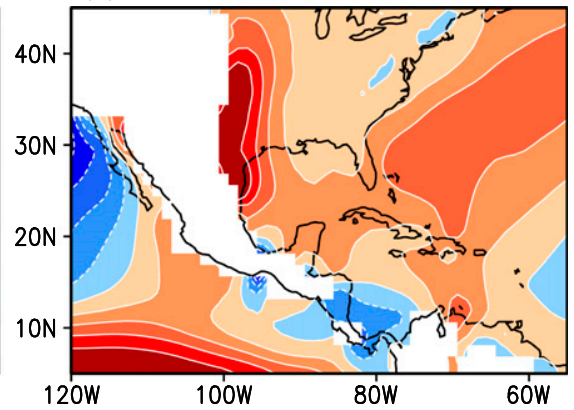

(d) $\mathrm{CM} 2.1$

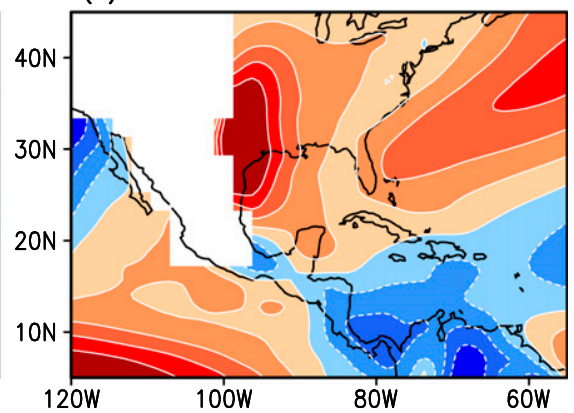

(f) FLOR

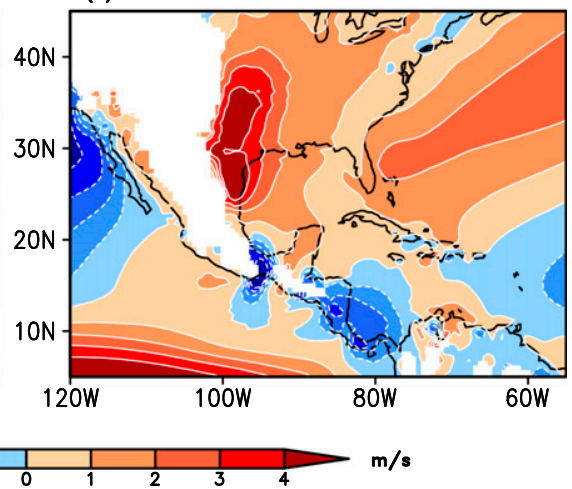

FIG. 2. Climatology of meridional winds at $925 \mathrm{hPa}\left(\mathrm{m} \mathrm{s}^{-1}\right)$ in AMJ for (a) MERRA, (c) CM2.1, and (e) FLOR and in JAS for (b) MERRA, (d) CM2.1, and (f) FLOR.

data when divided into 40-yr chunks, the standard deviation of the jet in few of the 40-yr periods show variability very similar to MERRA.

We also analyze the model's ability to capture the GPLLJ-rainfall relationship over the IAS and the United States (Fig. 4). MERRA suggests reduced rainfall over the southeastern United States and the Gulf of Mexico in the jet entrance region and enhanced rainfall over the northern part of the Great Plains in the jet exit region, during both AMJ and JAS seasons. FLOR shows slight improvement over CM2.1 in capturing the observed GPLLJ-rainfall association, especially over the jet exit region, in both the magnitude and spatial extent.

\section{2) Seasonal change in the GPLLJ-ENSO RELATIONSHIP}

Our results in section $3 \mathrm{a}(1)$ demonstrate that the FLOR model has relatively accurate simulation of the climatology and variability of the GPLLJ, which motivates us to use this model to understand the teleconnections to the GPLLJ from the adjacent oceans, with a particular focus on the relationship between ENSO and the GPLLJ during the GPLLJ's developing phase (AMJ) and during its peak and decay phase (JAS). Observational record suggests that the GPLLJ exhibits seasonal changes in its teleconnections with ENSO. A stronger GPLLJ is associated with La Niña-like 
(a) MERRA

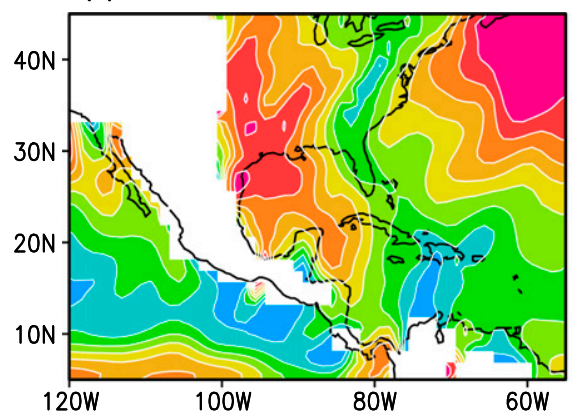

(c) $\mathrm{CM} 2.1$

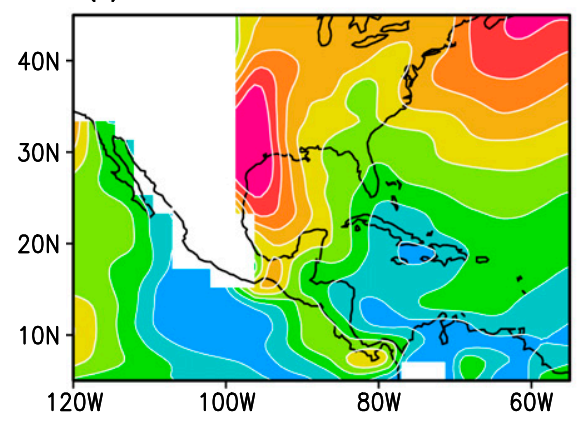

(e) FLOR

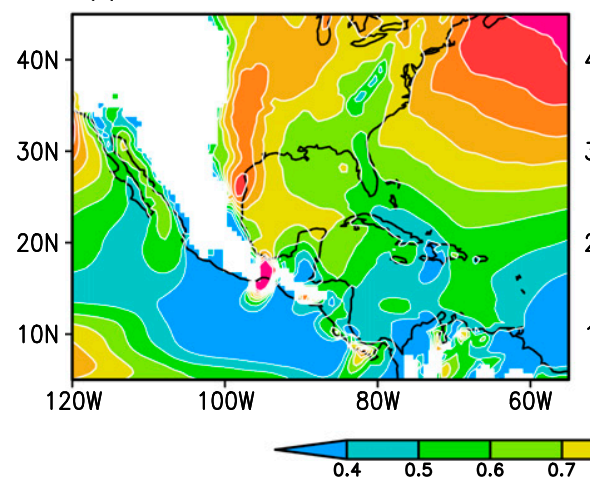

(b) MERRA

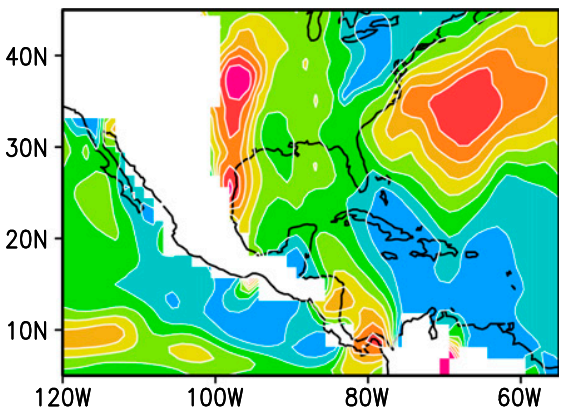

(d) $\mathrm{CM} 2.1$

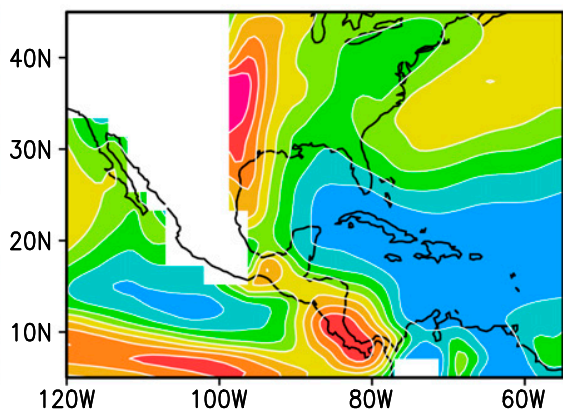

(f) FLOR

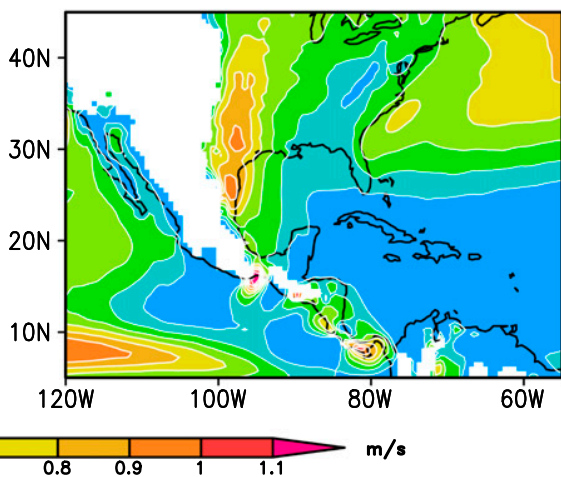

FIG. 3. Standard deviation of meridional winds at $925 \mathrm{hPa}\left(\mathrm{m} \mathrm{s}^{-1}\right)$ in AMJ for (a) MERRA, (c) CM2.1, and (e) FLOR and in JAS for (b) MERRA, (d) CM2.1, and (f) FLOR.

conditions in spring and El Niño-like conditions in summer (Fig. 1). Because of the limited sample size of observations, we test the robustness of the distinctive seasonality of the GPLLJ-ENSO relationship using the FLOR long control simulation.

The FLOR model shows that a stronger GPLLJ is associated with La Niña-like conditions in spring (Fig. 5), consistent with observations. It also recovers the relationship between the GPLLJ and the IAS SST dipole, with a stronger GPLLJ associated with cold SST anomalies in the Caribbean Sea and warm SST anomalies in the Gulf of Mexico as in observations (Weaver et al. 2009). However, the FLOR model fails to capture the positive correlation between the GPLLJ and tropical Pacific SSTs during summer, as it shows that a stronger GPLLJ is associated with La Niña-like conditions in contrast to observations. The analysis shown in Fig. 5 has been repeated for 50 -yr chunks of the $600-y r$ control simulation yielding similar results. Hence the model sampling cannot explain the differences with observations. Therefore, there is an inconsistency between this model and observations, and the seasonality of the GPLLJ-ENSO relation cannot be explained using the intrinsic multidecadal variability of this model.

In contrast, FLOR-FA, which by design has climatological SSTs close to observations, is able to successfully 
AMJ

(a) MERRA

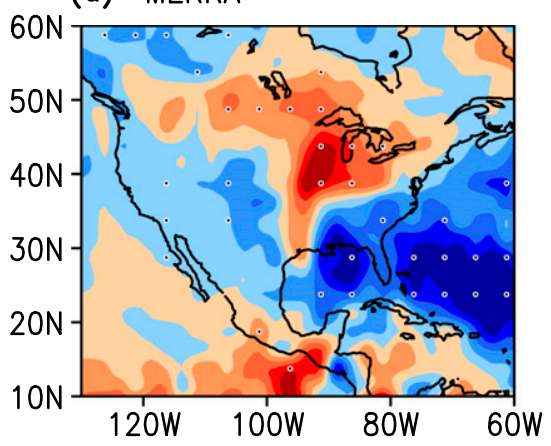

(c) $\mathrm{CM} 2.1$

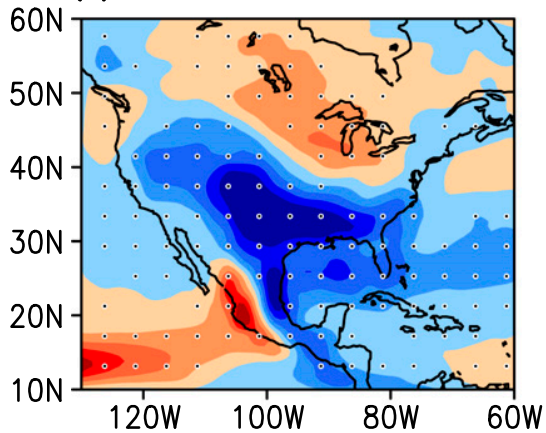

(e) FLOR

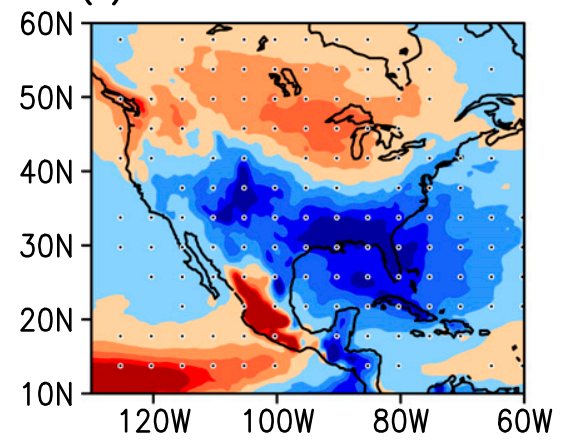

JAS

(b) MERRA

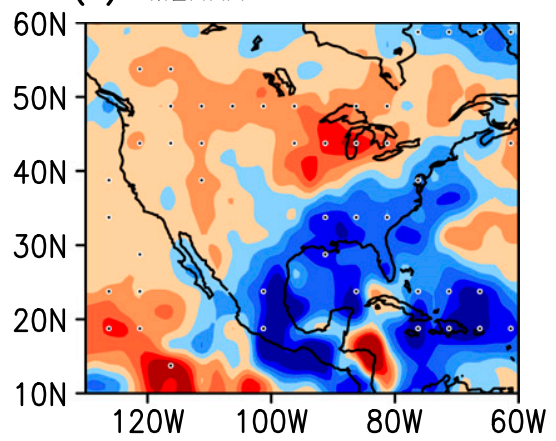

(d) $\mathrm{CM} 2.1$

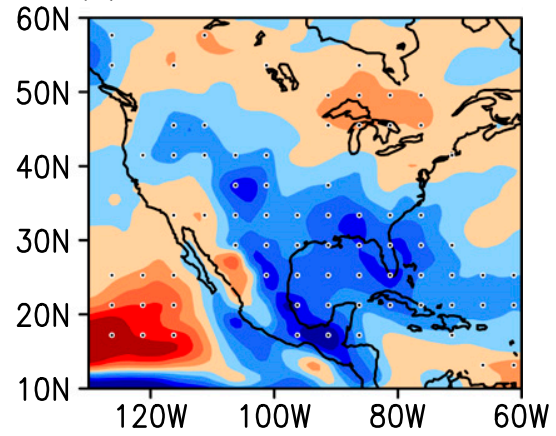

(f) FLOR

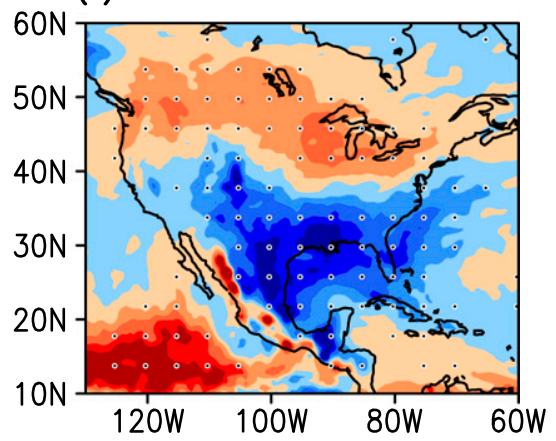

\section{$\begin{array}{llllllllll}-0.6 & -0.45 & -0.3 & -0.15 & 0 & 0.15 & 0.3 & 0.45 & 0.6\end{array}$}

FIG. 4. Regression of AMJ seasonal anomalies of precipitation on the AMJ seasonal GPLLJ for (a) MERRA, (c) CM2.1, and (e) FLOR. (b),(d),(f) As in (a),(c),(e), but for JAS. The dotted regions indicate $5 \%$ significance level. The units are in millimeters per day per std dev of the corresponding time series.

capture the seasonal change in the GPLLJ-ENSO relation (Fig. 6) that is seen in observations (Fig. 1). This suggests that the biases in FLOR SSTs, either resulting from local or nonlocal interactions, might be the reason for the discrepancy between FLOR and observations. We explore the differences between FLOR, FLOR-FA and observations to determine the source for such discrepancy. The mean state and variability of the GPLLJ are comparable in FLOR and FLOR-FA. The tropical Atlantic SSTs related to the GPLLJ are also very similar in the two models. This rules out the possibility of either the simulation of the GPLLJ or its related SSTs in the Atlantic as the main cause. Analysis of ENSO in FLOR and FLOR-FA reveals that the ENSO 
FLOR

(a) AMJ V925 and AMJ GPLLJ

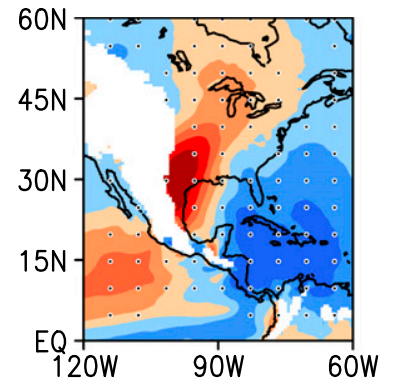

(b) JAS V925 and JAS GPLLJ

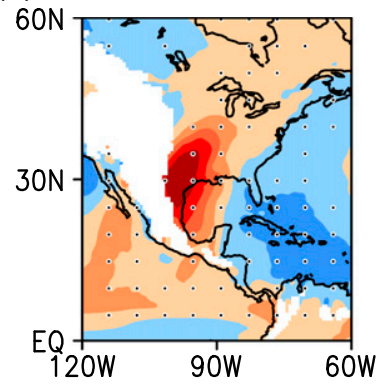

\begin{tabular}{llll|l|l|l|l|l|l}
-0.8 & -0.6 & -0.4 & -0.2 & 0 & 0.2 & 0.4 & 0.6 & 0.8
\end{tabular}

(c) AMJ SST and AMJ GPLLJ

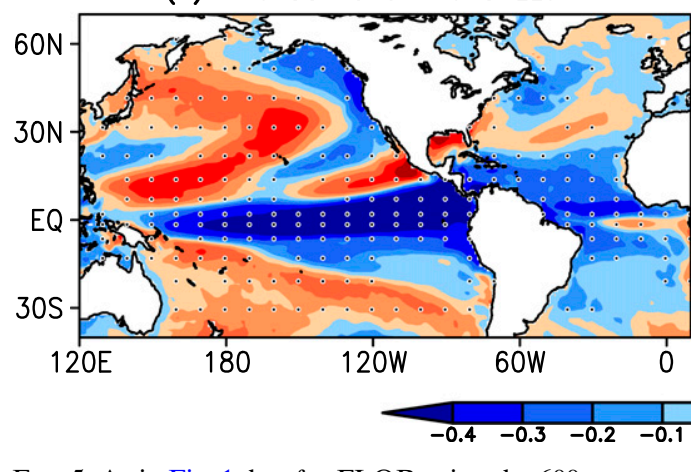

(d) JAS SST and JAS GPLLJ

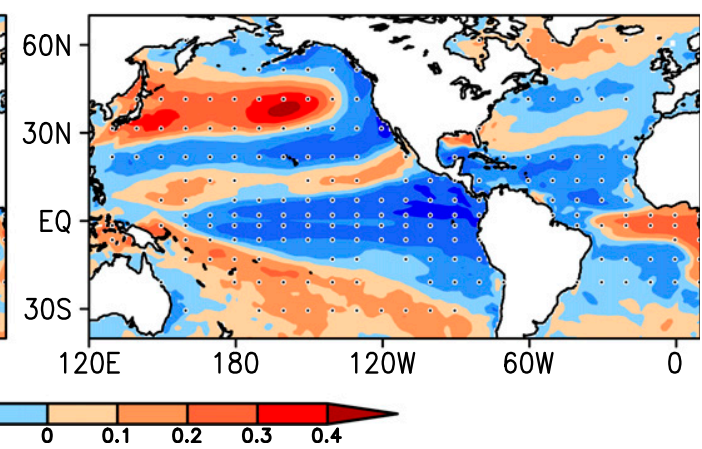

FIG. 5. As in Fig. 1, but for FLOR using the 600-yr control simulation. Panels (c),(d) are subject to field significance test and are significant at $5 \%$ significance level.

structure, amplitude, and phase locking is different between the two model simulations. In the next section, we explore the possibility of the differences in emergent behavior of ENSO to be the likely source of differences in simulating the seasonality of the GPLLJ-ENSO relation between FLOR and FLOR-FA.

\section{3) UNDERSTANDING THE LACK OF SEASONAL CHANGE IN THE GPLLJ-ENSO RELATION IN FLOR}

\section{(i) Role of the tropical Pacific SSTs}

We investigate the plausible reasons for the failure of FLOR to capture the seasonal change in the GPLLJENSO relation compared to FLOR-FA. We hypothesize that the improvement in FLOR-FA in simulating the GPLLJ-ENSO summer relationship arises from the better simulation of the phase locking and magnitude of ENSO variability compared to FLOR (Fig. 7). In the FLOR model, ENSO is not phase locked to the annual cycle and it exhibits stronger variability in FLOR compared to observations (Vecchi et al. 2014). Meanwhile, in FLOR-FA, ENSO amplitude is reduced and there is a more realistic simulation of phase locking of ENSO to the annual cycle (Fig. 7). To test the hypothesis that the improved ENSO representation in FLOR-FA yields improved GPLLJ-ENSO connection, we perform a sensitivity experiment, FLOR-FA_ENSO, in which FLOR is fully coupled except in the tropical Pacific Ocean where SSTs are restored to the monthly climatological SSTs from FLOR plus the monthly anomalies from FLOR-FA. In this experiment, labeled as FLOR-FA_ENSO, the tropical Pacific SST variability associated with ENSO is by design same as that in the FLOR-FA run.

The simulation of spring V925 and SST patterns related to a stronger GPLLJ in FLOR-FA_ENSO are similar to those in FLOR and FLOR-FA runs (Fig. 8) and consistent with observations. In this experiment the model shows the seasonal change in the GPLLJ-ENSO relation from spring to summer with a stronger GPLLJ associated with La Niña-like conditions in spring and El Niño-like conditions in summer. This supports our hypothesis that the better phase locking and amplitude of ENSO in FLOR-FA improves its summer teleconnection with the GPLLJ. This experiment demonstrates the importance of accurately simulating the phase locking of ENSO in the coupled climate models in order to capture the seasonal change in the teleconnections associated with ENSO in the IAS and over 
FLOR-FA

(a) AMJ V925 and AMJ GPLLJ

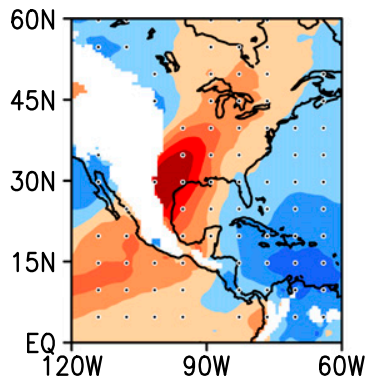

(b) JAS V925 and JAS GPLLJ

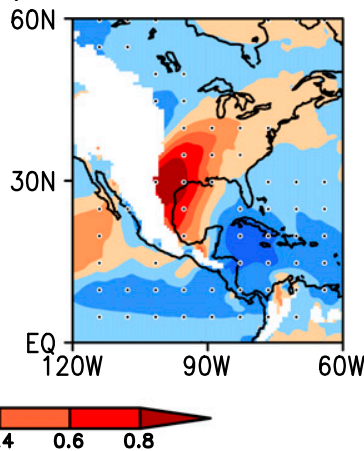

(c) AMJ SST and AMJ GPLLJ

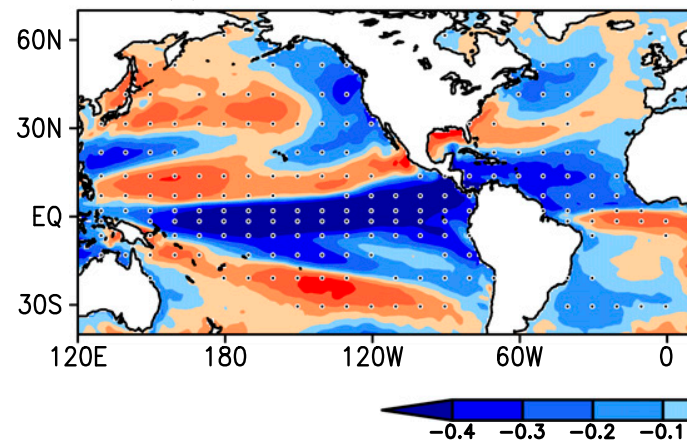

(d) JAS SST and JAS GPLLJ

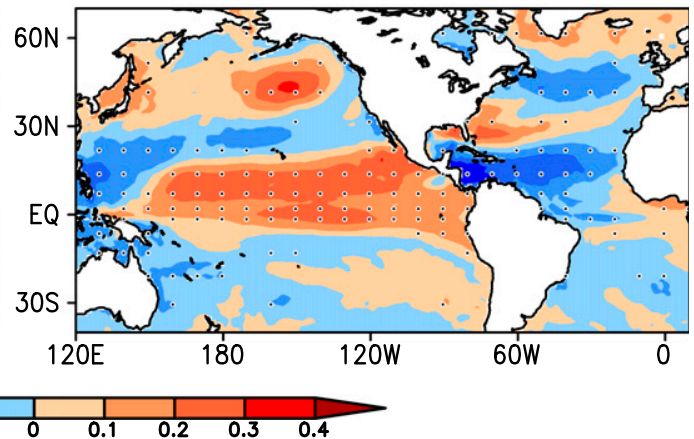

FIG. 6. As in Fig. 1, but for FLOR-FA using the 500-yr simulation. Panels (c),(d) are subject to field significance test and are significant at $5 \%$ significance level.

the North American climate. We further hypothesize that correctly simulating the seasonal phase locking of ENSO may be crucial to capturing other ENSO teleconnections around the globe.

\section{(ii) Role of the North Pacific SSTs}

The GPLLJ-ENSO summer teleconnection improves from a more realistic SST variability in the tropical Pacific, but in FLOR-FA_ENSO, the connection between enhanced summer GPLLJ and El Niño is not as strong as in observations or as in FLOR-FA. We explore the possibility of other factors interfering with the GPLLJENSO relation. In particular, we focus on the influence of the North Pacific SSTs or inaccurate tropicalextratropical interactions.

Several studies have suggested the influence of the North Pacific SSTs on the central U.S. climate. For example, Hu and Huang (2009) suggest that the warm phase of the Pacific decadal oscillation (PDO) is associated with the wet Great Plains and cold phase is associated with dry conditions over the Great Plains. Besides, a stronger GPLLJ also leads to wet Great Plains, thus the warm phase of the PDO may be associated with a stronger GPLLJ. Ting and Wang (1997) draw similar conclusions as $\mathrm{Hu}$ and Huang (2009) for the PDO-Great Plains summer teleconnection. They conclude that the atmospheric circulation over the United States depends on both the tropical and the

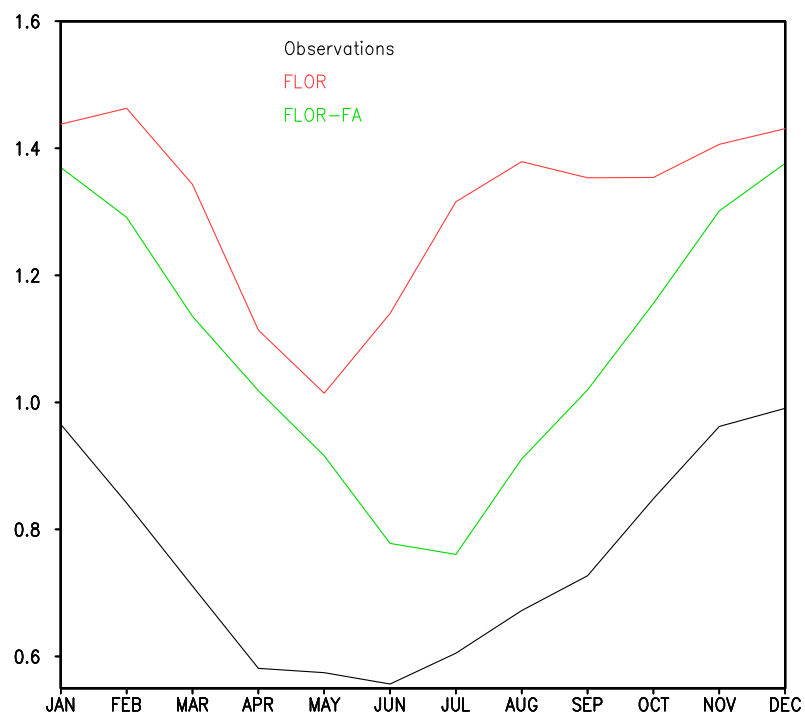

FIG. 7. Standard deviation of monthly Niño-3.4 index $\left({ }^{\circ} \mathrm{C}\right)$ for HadISST (black), FLOR (red), and FLOR-FA (green). 
(a) AMJ V925 and AMJ GPLLJ

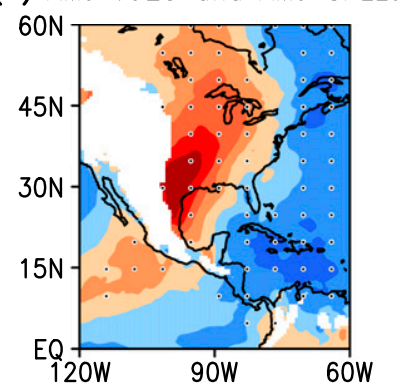

(b) JAS V925 and JAS GPLLJ

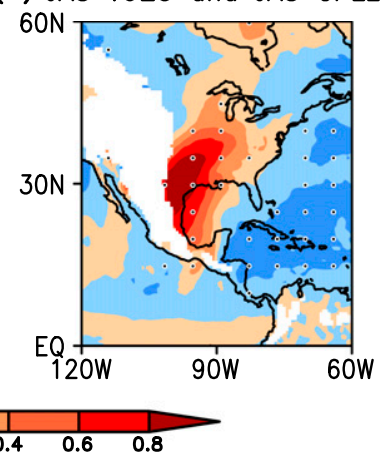

(c) AMJ SST and AMJ GPLLJ

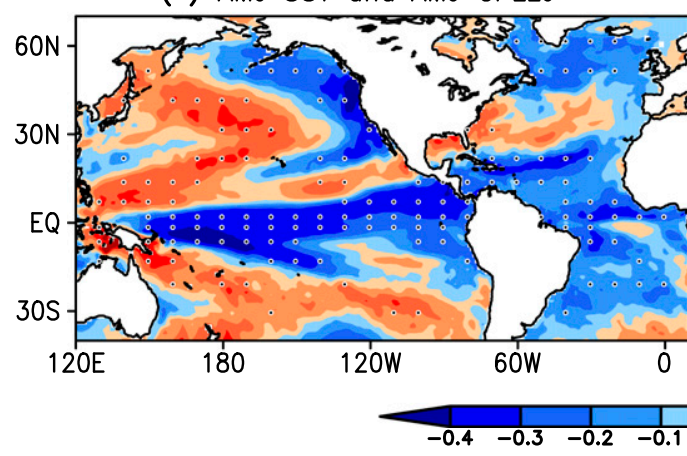

(d) JAS SST and JAS GPLLJ

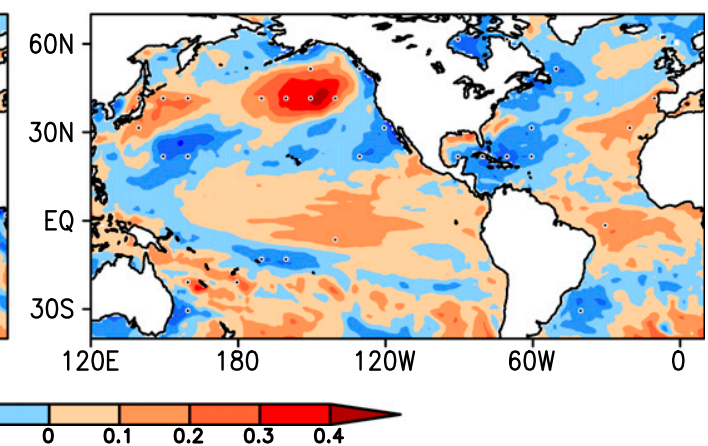

FIG. 8. As in Fig. 1, but for the 100-yr FLOR-FA_ENSO experiment.

extratropical SSTs. Weaver et al. $(2012,2013)$ also suggest the strengthening of the GPLLJ with the warm phase of PDO. Schubert et al. (2004) results from observational and model analysis are consistent and suggest that the tropical Pacific SSTs and the low-frequency pan-Pacific SSTs contribute to the variability of the summer rainfall over the Great Plains. FLOR is shown to have a realistic simulation of PDO teleconnection with rainfall over North America (Zhang and Delworth 2015, manuscript submitted to J. Climate).

We characterize the relation between the GPLLJ and the Pacific SSTs using composites of SST isolating the strong GPLLJ events during AMJ and JAS. All simulations (FLOR control, FLOR-FA, and FLOR-FA_ ENSO) suggest that the cold phase of the PDO-like anomalies (positive SSTs in the central North Pacific) are related to a stronger GPLLJ in summer (Figs. 5d, 6d, $8 \mathrm{~d}$, and $9 \mathrm{~d}, \mathrm{f})$. This is in contrast to observations, where the warm phase of PDO-like anomalies (negative SSTs in the central Pacific) is associated with a stronger GPLLJ (Figs. 1d and 9b). Thus, the negative tropical SSTs related to the cold PDO-like phase might be counteracting the positive SSTs associated with El Niño during summer, leading to a weaker positive correlation in FLORFA_ENSO. This is a preliminary hypothesis that needs further investigation and will be explored in future work. The FLOR-FA-no_ENSO experiment (where the ENSO variability is suppressed by restoring SSTs to climatology in the tropical Pacific Ocean) does show the opposite relation between the North Pacific SSTs and the summer GPLLJ (Fig. 9h) independent of ENSO, suggesting a secondary yet crucial role played by the North Pacific SSTs on the GPLLJ variability.

\section{Discussion of the mechanistic hypothesis for the GPLLJ-ENSO relation}

It is intriguing that a stronger GPLLJ is associated with different phases of ENSO during spring and summer seasons. We use observed relationships and our model experiments to suggest a mechanism through which $\mathrm{La}$ Niña-like conditions in spring and El Niño-like conditions in summer can maintain a stronger GPLLJ.

\section{a. Tropical mechanism}

\section{1) OBSERVATIONALly MOTIVATED MECHANISTIC HYPOTHESIS}

The GPLLJ draws moisture from the tropical Atlantic through the CLLJ (Munoz and Enfield 2011). Thus, the 


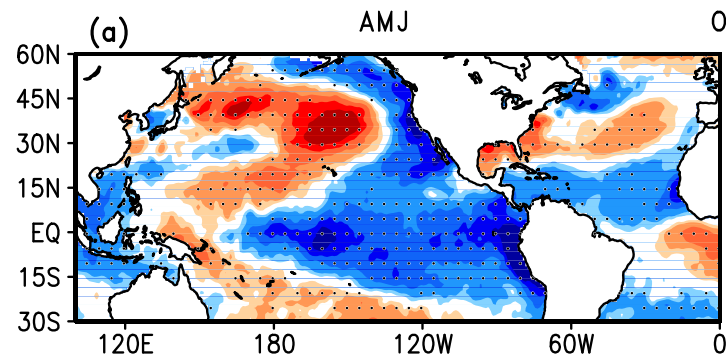

OBS

JAS

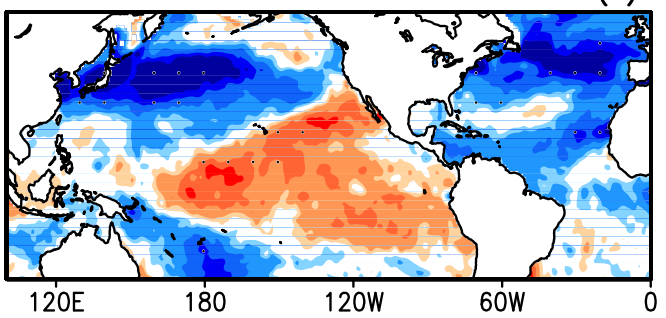

(c) FLOR

(d)
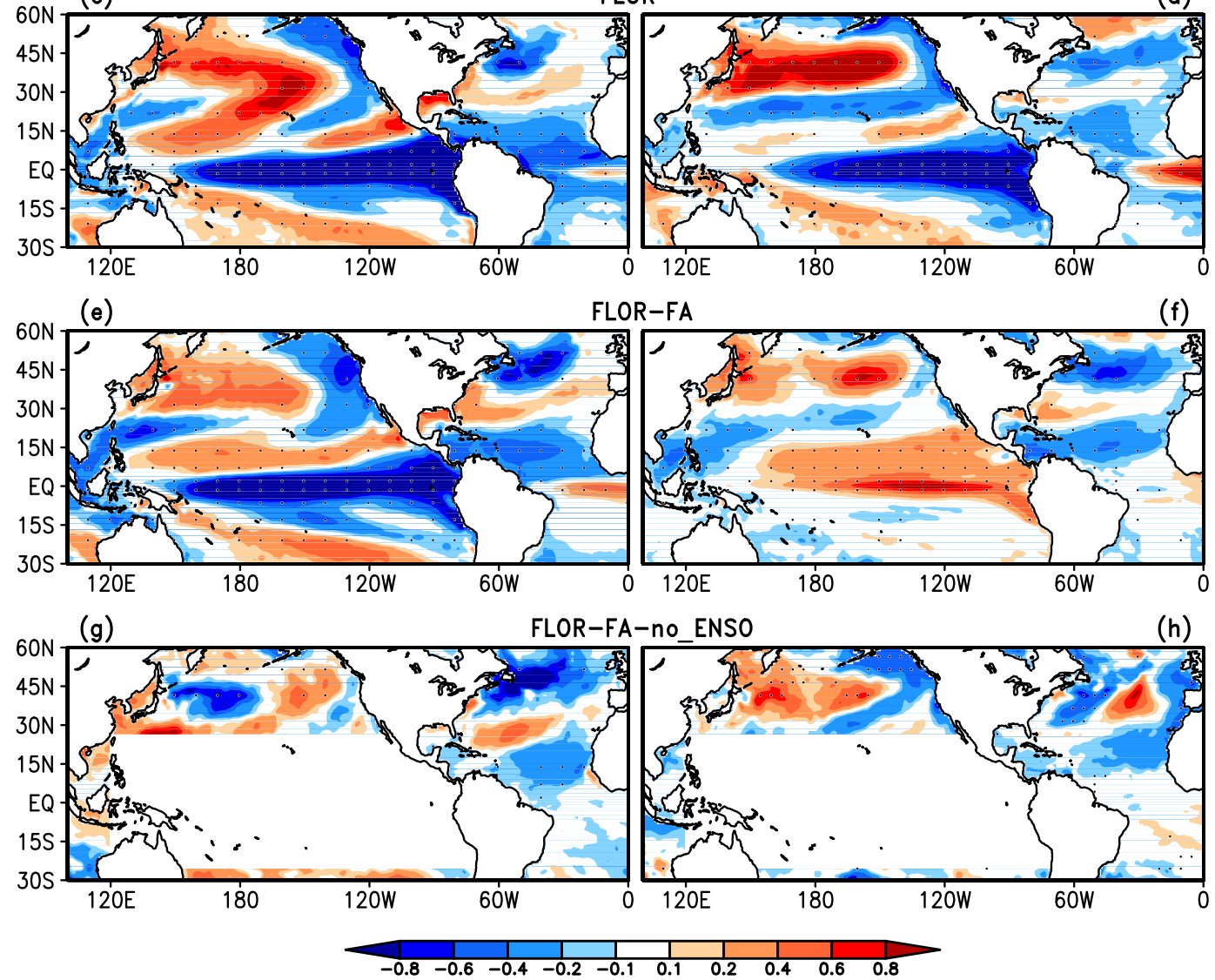

FIG. 9. Strong-weak GPLLJ composites of AMJ SST anomalies ( $\left({ }^{\circ} \mathrm{C}\right)$ in (a) observations, (c) FLOR, (e) FLOR-FA, (g) FLOR-FA-no_ENSO. (b),(d),(f),(h) As in (a),(c),(e),(g), but for JAS. The strong (weak) GPLLJ is chosen when the standardized GPLLJ index is greater (less) than $1(-1)$ std dev. The number of years included in the AMJ composites are 15 (12), 100 (102), 104 (98), and 12 (14) for a stronger (weaker) GPLLJ for NCEP-NCAR, FLOR, FLOR-FA, and FLOR-FA-no_ENSO, respectively. Similarly, the number of years included in the JAS composites are 9 (11), 95 (104), 71 (81), and 13 (15) for a stronger (weaker) GPLLJ in NCEP-NCAR, FLOR, FLOR-FA, and FLOR-FA-no_ENSO, respectively. The dotted regions indicate 5\% significance level.

strength of the GPLLJ and its moisture transport toward the central United States depend on the atmospheric and oceanic conditions over the tropical Atlantic. Here, we propose a mechanism that explains the effect of ENSO on the GPLLJ via the tropical Atlantic. Previous observational and modeling studies showed that ENSO is associated with significant atmospheric anomalies (SLP and winds) in the tropical
Atlantic through the Walker and Hadley circulations, with a 2-5-month lag (Enfield and Mayer 1997; Giannini et al. 2000; Alexander and Scott 2002; Wang 2005, 2006). Figures $10 \mathrm{a}-\mathrm{c}$ indicate that the wintertime La Niña is followed by significant atmospheric and oceanic anomalies in the tropical Atlantic, consistent with these previous studies. The spring SSTs that follow the winter ENSO are characterized by a La Niña-like 

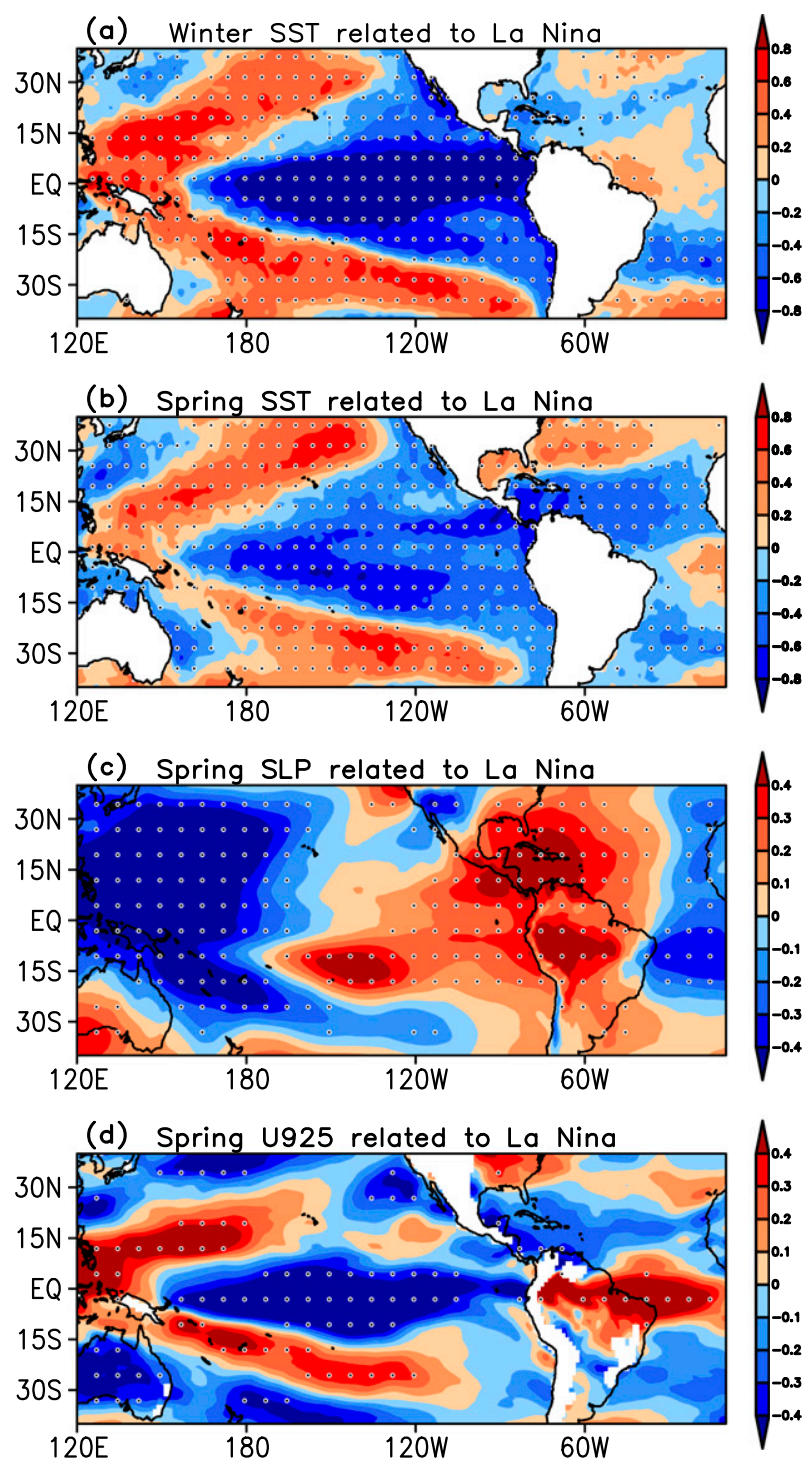

FIG. 10. Observed point correlation between DJF seasonal Niño-3.4 and (a) DJF SST anomalies, (b) AMJ SST anomalies (Niño-3.4 leads), (c) AMJ SLP anomalies (Niño-3.4 leads), and (d) AMJ zonal wind anomalies at $925 \mathrm{hPa}$ (Niño-3.4 leads). Winds are based on MERRA and SST is from HadISST for the period 1979-2013. The dotted regions indicate 5\% significance level.

phase in the tropical Pacific, positive SSTs anomalies over the Gulf of Mexico, and negative SSTs over the Caribbean Sea. These La Niña-like anomalies drive the subsidence (via the Walker and Hadley circulations, as shown in Fig. 11) and high SLP anomalies over the IAS, leading to stronger easterlies in the Caribbean region during the following spring season (Figs. 10c,d), which corresponds to a stronger CLLJ [area-averaged zonal winds at $925 \mathrm{hPa}$ (U925) within $12^{\circ}-16^{\circ} \mathrm{N}, 70^{\circ}-$ $\left.80^{\circ} \mathrm{W}\right]$. The enhanced CLLJ increases evaporative cooling and has a positive feedback on the atmosphere reinforcing and strengthening the SLP over the Gulf Coast of the United States, consistent with the study of Wang (2007). In MERRA, the CLLJ and GPLLJ indices are anticorrelated $(r=-0.43)$, suggesting that the high SLP and a stronger CLLJ in the IAS are associated with a stronger GPLLJ, consistent with the SLP and zonal wind anomalies shown in Figs. 12a,c.

A different mechanism is needed to explain why the El Niño-like conditions are associated with a stronger GPLLJ in summer. A stronger GPLLJ in summer is associated with the low SLP anomalies in the tropical Pacific, which is a characteristic of an El Niño phase, and the high SLP anomalies in the tropical Atlantic (Fig. 12b). The high SLP anomalies in the tropical Atlantic arise from the local ocean-atmosphere feedback. Indeed, during ENSO, the oceanic anomalies in the tropical Atlantic persist from spring to summer, which favors a positive feedback on the overlying atmosphere and contributes to maintaining of the atmospheric anomalies (high SLP) over the IAS region (Giannini et al. 2000; Alexander and Scott 2002). The supporting evidence for the role of SLP over the IAS in strengthening the GPLLJ is also shown through the model experiments by Weaver et al. (2009). The opposite SLP anomalies between the tropical Pacific and Atlantic Oceans result in a SLP gradient that favors stronger easterlies and thus a stronger CLLJ (Fig. 12d). This is consistent with results of Giannini et al. (2000) and Wang (2006) suggesting that the seesaw of SLP between the tropical Pacific and the Atlantic Oceans enhances the divergence over the Caribbean region affecting the trade winds. Similar features are found for the SLP and U925 anomalies associated with a stronger CLLJ (not shown). As in spring, in MERRA, a stronger CLLJ (easterlies over the Caribbean Sea) is associated with a stronger GPLLJ (southerlies over Great Plains) during summer $(r=-0.47)$. Thus, we suggest that the link during summer between the tropical Pacific and the GPLLJ is determined by the SLP gradient between the tropical Pacific and Atlantic Oceans and is further enhanced and maintained by the response of the CLLJ to this SLP gradient.

\section{2) EVIDENCE FOR MECHANISTIC HYPOTHESIS IN FLOR-FA}

We explore the FLOR-FA model's ability to capture the mechanism hypothesized from observations (Fig. 13). We examine this mechanism in FLOR-FA instead of FLOR, as only the former captures the seasonal change in the relationship between ENSO and the GPLLJ. Figures 13a,c show spring SLP and U925 
(a) Walker Circulation $(5 S-5 N)$

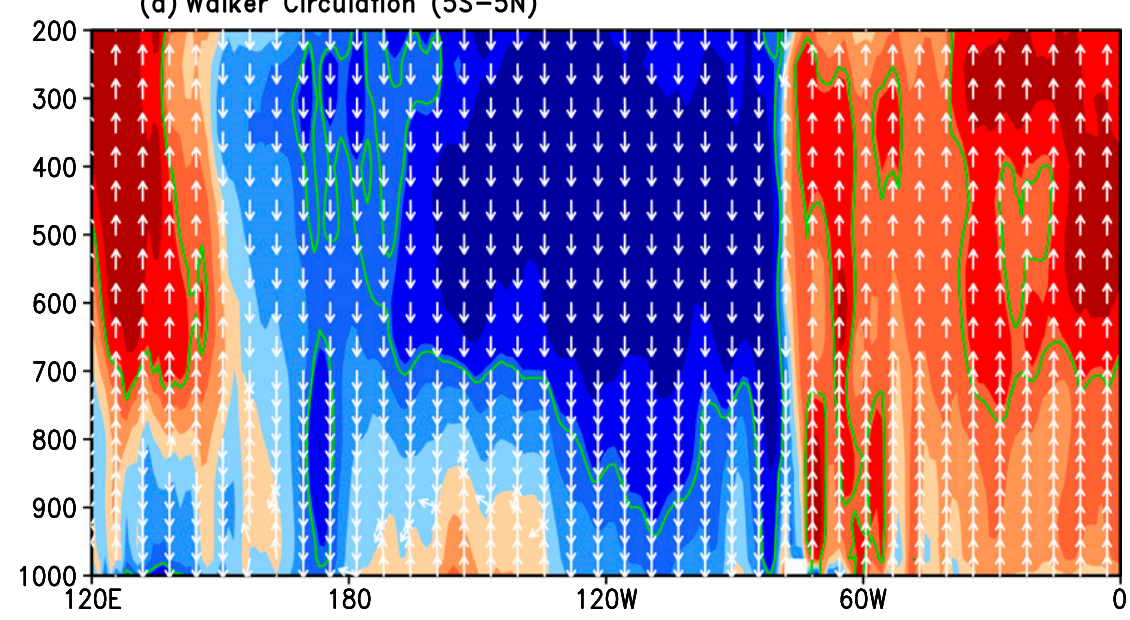

(b) Hadley Circulation (50W-70W)

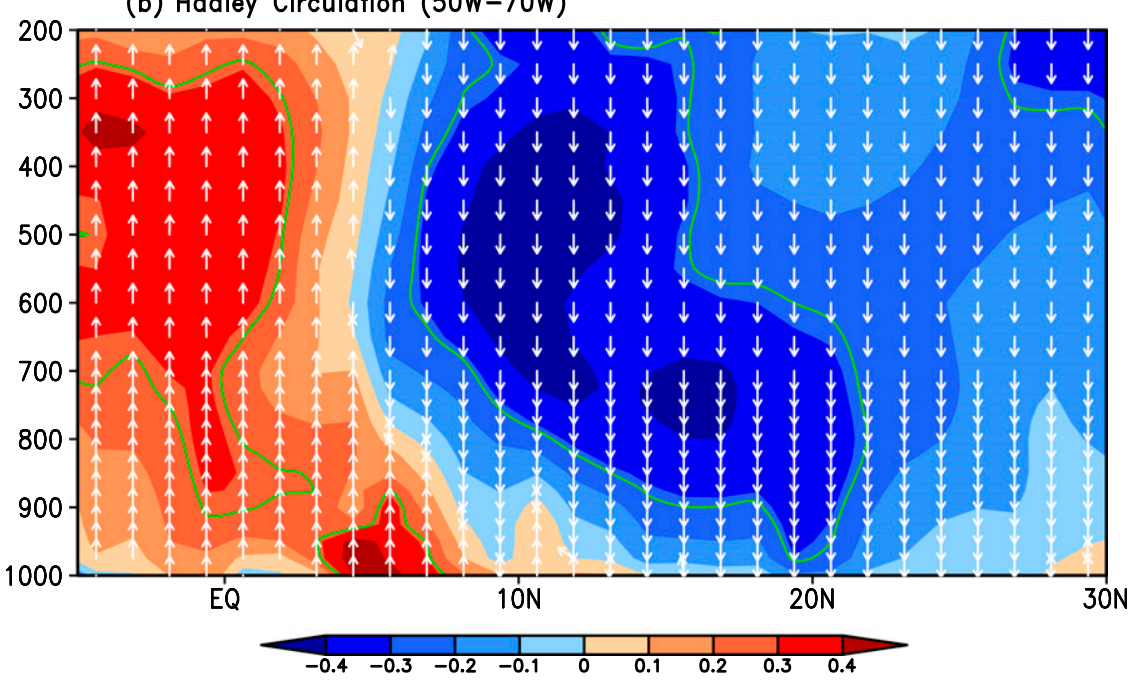

FIG. 11. Point correlation between DJF seasonal Niño-3.4 and AMJ vertical velocity anomalies $(-w)$ to depict (a) Walker circulation averaged between $5^{\circ} \mathrm{S}$ and $5^{\circ} \mathrm{N}$ and (b) Hadley circulation averaged between $50^{\circ}$ and $70^{\circ} \mathrm{W}$. The correlations are shaded and the vectors are shown to depict ascending and descending motion. The green contoured regions indicate $5 \%$ significance level.

anomalies in phase with a stronger GPLLJ. A stronger GPLLJ is associated with the high SLP anomalies along the coast of Florida (SLP variability determined by preceding La Niña as suggested in observations). The high SLP leads to stronger easterlies implying a stronger CLLJ. As seen in Fig. 13c, a stronger CLLJ (easterlies) is related to a stronger GPLLJ. Thus, the model results suggest that FLOR-FA successfully captures the tropical atmospheric link between the GPLLJ and the tropical Pacific SSTs through the CLLJ in spring. The simulated mechanism for summer is illustrated in Figs. 13b,d,f. During summer, the model captures the observed SLP gradient pattern between the tropical
Pacific and Atlantic as well as the trade wind signature that is favorable for a stronger GPLLJ, consistent with observations.

\section{b. Extratropical mechanism in observations and model}

We hypothesize that ENSO can also influence the GPLLJ through an extratropical atmospheric bridge (Figs. 13e,f). During spring, ENSO drives a PacificNorth American (PNA) pattern (Horel and Wallace 1981), which also affects the GPLLJ-related circulation in the IAS. During summer, the 500-hPa geopotential height anomalies associated with a stronger 


\section{Observations}

(a) AMJ SLP and AMJ GPLLJ

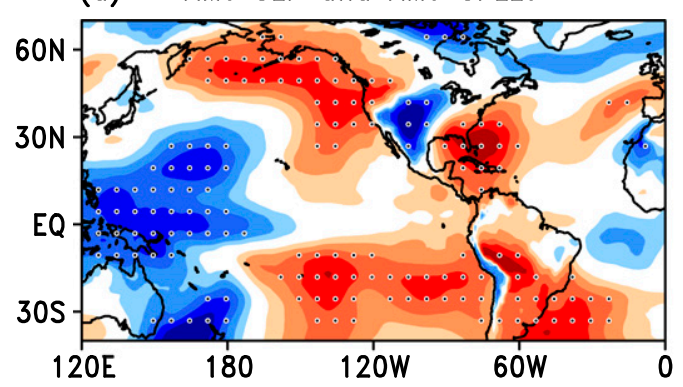

(c) AMJ U925 and AMJ GPLLJ

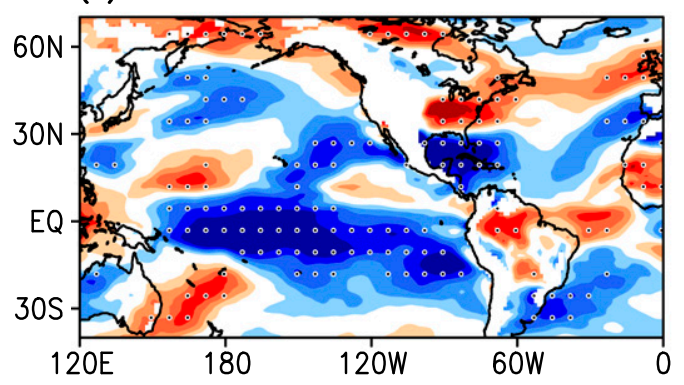

(b) JAS SLP and JAS GPLLJ

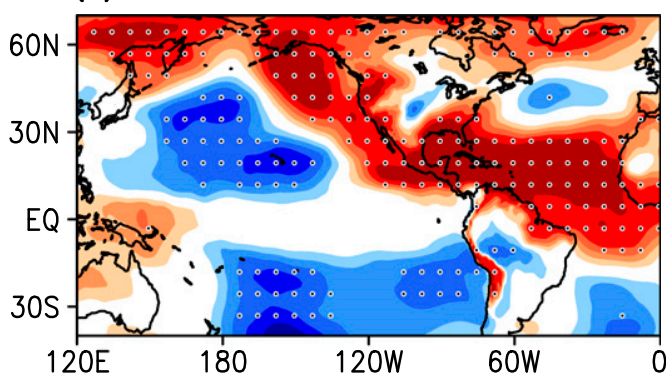

(d) JAS U925 and JAS GPLLJ

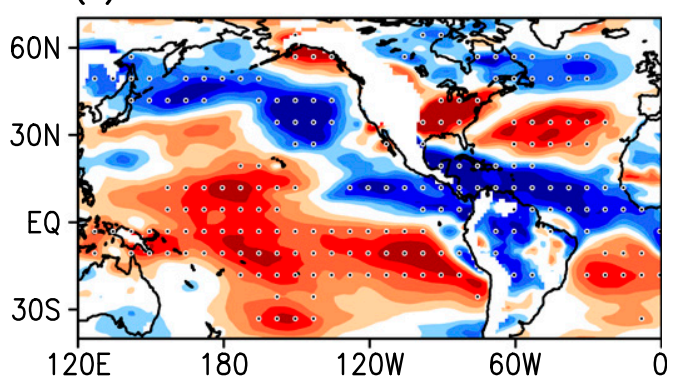

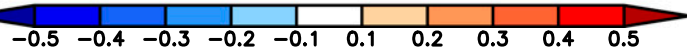

FIG. 12. Point correlation between the AMJ seasonal GPLLJ and AMJ seasonal anomalies of (a) SLP and (c) zonal wind at $925 \mathrm{hPa}$. Point correlation between the JAS GPLLJ and JAS seasonal anomalies of (b) SLP and (d) zonal wind at $925 \mathrm{hPa}$. SLP and winds are based on MERRA for 1979-2013. The dotted regions indicate 5\% significance level.

GPLLJ represents the wave train emanating from the tropical western Pacific region. This is consistent with Weaver et al. (2009), who show similar patterns in observations (but for 200-hPa heights). FLOR-FA successfully captures these extratropical patterns as seen in the Figs. 13e,f (cf. observed patterns in Fig. 14). The geopotential height patterns determined using the PNA index resemble the anomalies shown in Figs. 13e,f (figure not shown). The winter PNA pattern is also simulated in FLOR (Yang et al. 2015) and the continental teleconnections of ENSO ( $\mathrm{Jia}$ et al. 2015). However, the spring tropical connection is stronger in FLOR-FA than in MERRA (Fig. 14a), although it shows good correspondence with NCEPNCAR (Fig. 14c). The apparent differences in agreement between the model and different reanalysis patterns might be related to the inherent issues in the reanalysis products such as changes in the observing system after the 1970s (NCEP-NCAR), trends in geopotential heights (MERRA), and sampling variability between NCEP-NCAR (1948-2009) and MERRA (1979-2013). We also compared the extratropical connections with ERA-Interim and CFSR (figure not shown). The extratropical signature compares well among all the reanalysis products and model with minor differences in the tropics.

\section{c. Simulated mechanistic hypothesis in FLOR-FA-no_ENSO}

The proposed tropical and extratropical mechanisms are finally explored in the experimental run with no ENSO variability (FLOR-FA-no_ENSO), to provide further insight into the relative roles of the tropical and extratropical bridges in connecting the tropical Pacific to the GPLLJ. In FLOR-FA-no_ENSO simulation, the tropical Pacific SSTs are restored to monthly climatological values to mask the ENSO variability. Although ENSO is absent in this experimental run, we still notice SLP and zonal wind anomalies associated with a stronger GPLLJ in spring (Figs. 15a,c). The variability projects onto the PNA pattern (independent of ENSO, as the tropical atmospheric footprint associated with it is absent; cf. Fig. 13e), involving low geopotential heights over Canada and positive heights over the southeastern United States (Fig. 15e), and it determines the SLP anomalies over the IAS (Fig. 15a) that further drive the 


\section{FLOR-FA}

(a) AMJ SLP and AMJ GPLLJ

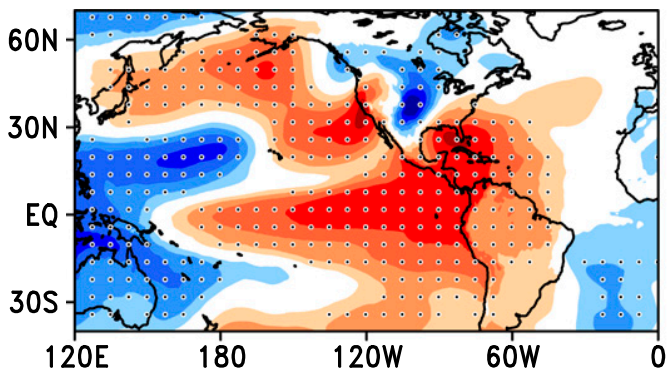

(c) AMJ U925 and AMJ GPLLJ

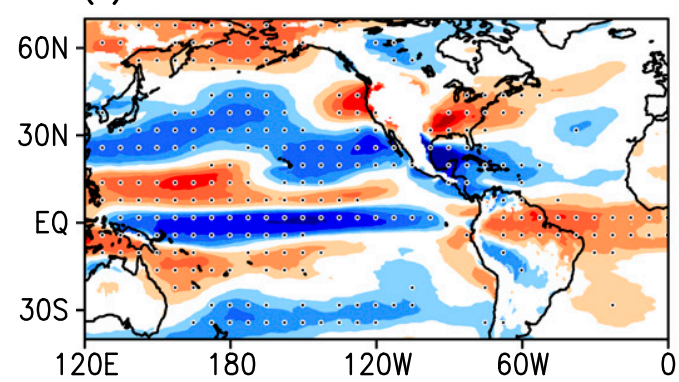

(e) AMJ HGT500 and AMJ GPLLJ

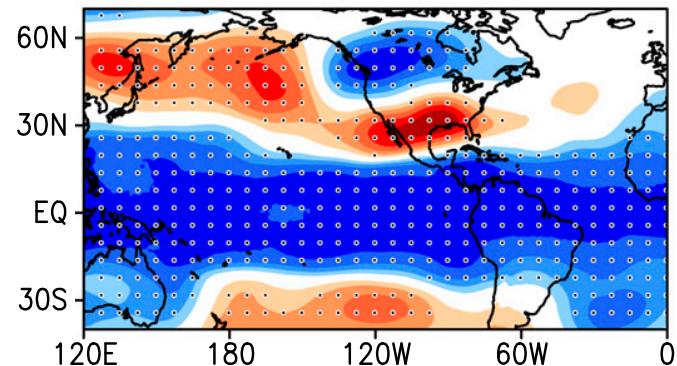

(b) JAS SLP and JAS GPLLJ

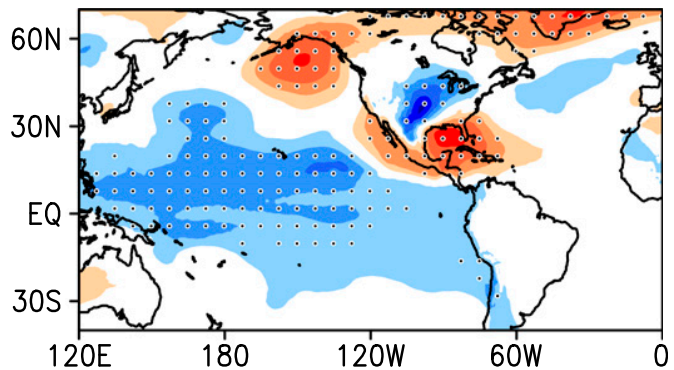

(d) JAS U925 and JAS GPLLJ

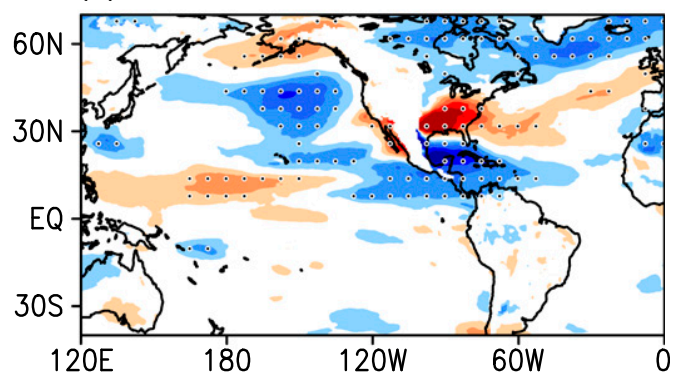

(f) JAS HGT500 and JAS GPLLJ

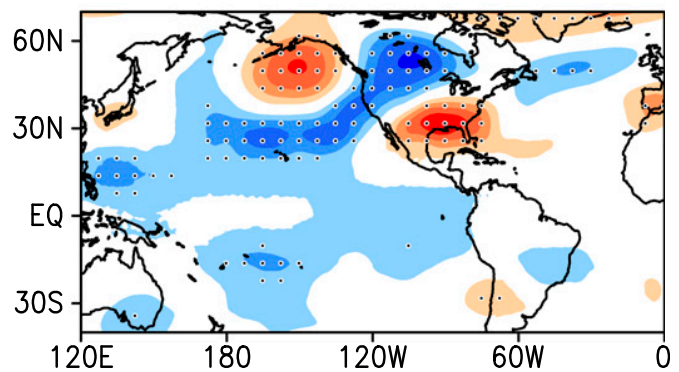

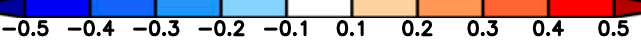

FIG. 13. Point correlation between AMJ seasonal GPLLJ and AMJ seasonal anomalies of (a) SLP, (c) zonal wind at $925 \mathrm{hPa}$, and (e) 500-hPa geopotential height in the FLOR-FA run. (b),(d),(f) As in (a),(c),(e), but for JAS. The dotted regions indicate $5 \%$ significance level.

variability of zonal (Fig. 15c) and meridional winds in the IAS. Thus, from Figs. 13e and 15e, we can conclude that the PNA variability, independent of its connection to ENSO, impacts the GPLLJ in spring.

Meanwhile, during summer, the principal connection between the Pacific and the IAS atmospheric circulation anomalies related to a stronger GPLLJ is through the tropics (Figs. 15b,d,f). The high SLP signature along the coast of Florida is extremely weak in FLOR-FA-no_ENSO, as are the easterlies associated with the CLLJ in the Caribbean region. Thus, the tropical link through which ENSO affects the GPLLJ seems to be more prominent during summer than in spring. We speculate that this may be because, in spring, the climatological differences in the extratropical circulation make the PNA response stronger than in summer. In summer, the PNA variability is much weaker and it cannot serve as an effective conduit of information from the tropics to maintain a stronger GPLLJ (Fig. 15f).

\section{Conclusions and discussion}

We have explored seasonal changes of the relationship between the GPLLJ and ENSO, focusing on boreal spring to summer. Observations suggest that a stronger GPLLJ is related to cold tropical Pacific SSTs (La Niñalike conditions) in spring and to warm tropical Pacific 
(a) MERRA: AMJ HGT500 and AMJ GPLLJ

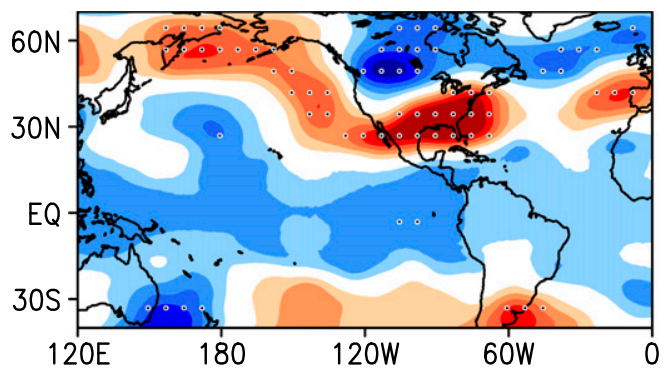

(c) NCEP-NCAR: AMJ HGT500 and AMJ GPLLJ

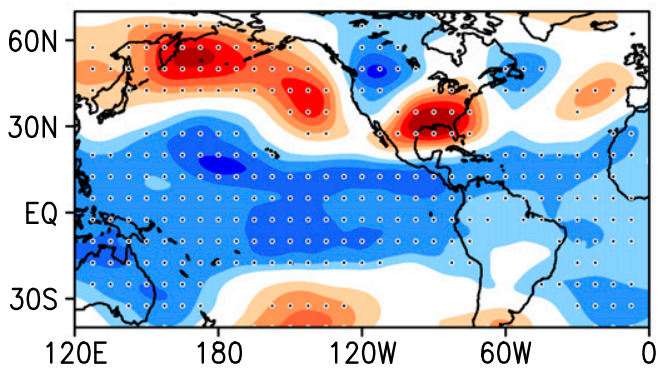

(b) MERRA: JAS HGT500 and JAS GPLLJ

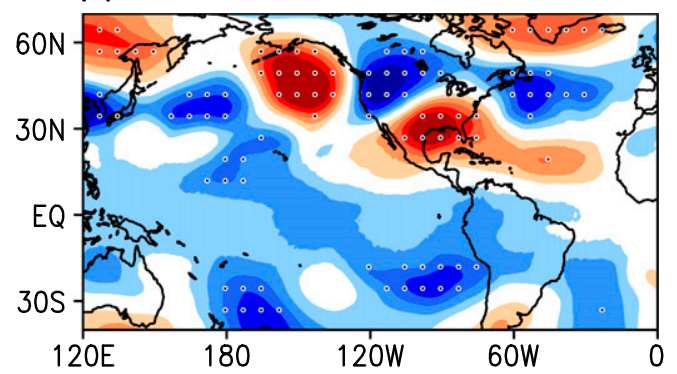

(d) NCEP-NCAR: JAS HGT500 and JAS GPLLJ

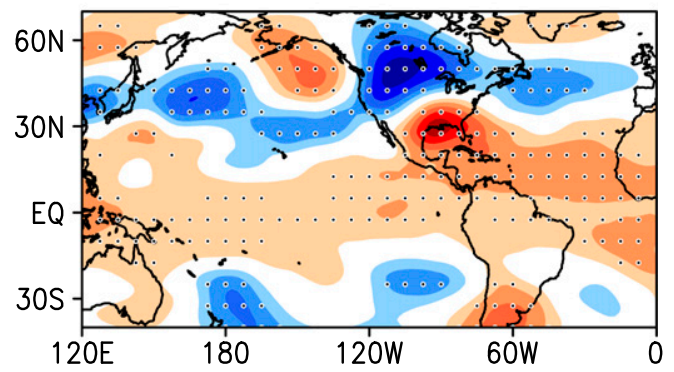

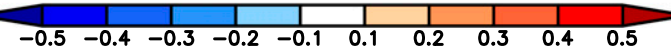

FIG. 14. Point correlation between the AMJ GPLLJ and (a),(c) AMJ and (b),(d) JAS seasonal anomalies of 500hPa geopotential height for (a),(b) MERRA for the period 1979-2013 and (c),(d) NCEP-NCAR for the period 19482009. The wave patterns are shown for 500-hPa geopotential heights motivated from Wallace and Gutzler (1981) for the definition of PNA teleconnection pattern. The dotted regions indicate $5 \%$ significance level.

SSTs (El Niño-like conditions) in summer. Using a series of integrations with global coupled models, we investigated whether the observed seasonal change in the GPLLJ-ENSO relation could be considered as a statistical artifact and explored the mechanism behind it.

We have analyzed the GPLLJ-ENSO relationship in the state-of-the-art GFDL FLOR coupled climate model that has high-resolution atmospheric and land components. In section $3 \mathrm{a}(2)$, we showed that the standard version of FLOR fails to simulate the seasonal change in the GPLLJ-ENSO relation. The histogram of correlations based on 40-yr chunks of model data (Figs. 16a,b) suggests that the correlations between the ENSO and GPLLJ are negative during both the spring and summer seasons in FLOR. Thus, the simulated intrinsic variability of the GPLLJ-Pacific relationship in FLOR could not explain the failure of FLOR in simulation of the observed seasonal change in the GPLLJENSO relationship.

However, FLOR-FA, in which the simulated SST climatology is maintained close to observations via flux correction, successfully captures the seasonal change in the GPLLJ-ENSO relation. The FLOR-FA model results suggest that the observed seasonal change in
GPLLJ-ENSO relation reflects a systematic feature of the climate system and that the FLOR model, despite its increased atmospheric resolution and improved mean state (Jia et al. 2015), remains sufficiently biased that it fails to capture this relationship. In the FLORFA, a stronger GPLLJ is associated with La Niña-like conditions in spring and with El Niño-like conditions in summer, similar to observations. In FLOR-FA, the correlations are negative during spring and predominantly positive during summer, suggesting a seasonal change in the relationship during most of the 40-yr chunks (Figs. 16c,d).

We have investigated the reasons for the absence of seasonality in the GPLLJ-ENSO relation in FLOR. The variability of the GPLLJ and its relation to the Atlantic does not show considerable difference between FLOR and FLOR-FA. The principal differences in GPLLJENSO relationship seem to arise in the simulation of the tropical Pacific SST variability between FLOR and FLOR-FA. ENSO in FLOR shows stronger variability and inaccurate phase locking compared to observational estimates. These errors are reduced in FLOR-FA. Using coupled model experiments where the tropical Pacific variability was restored to FLOR-FA anomalies, we showed that it is crucial to capture the phase locking of 
(a) AMJ SLP and AMJ GPLLJ

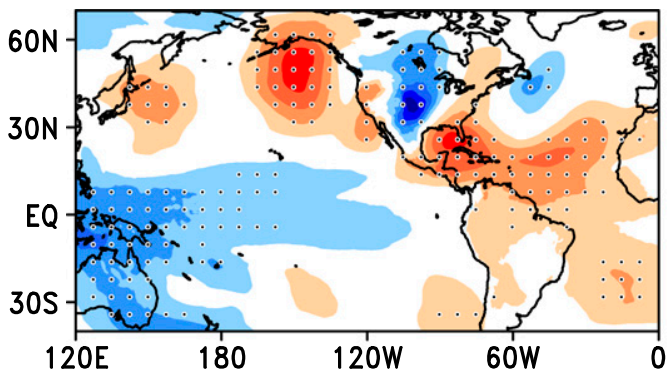

(c) AMJ U925 and AMJ GPLLJ

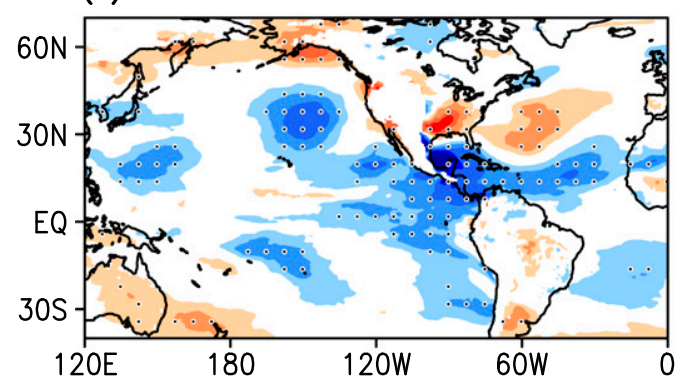

(e) AMJ HGT500 and AMJ GPLLJ

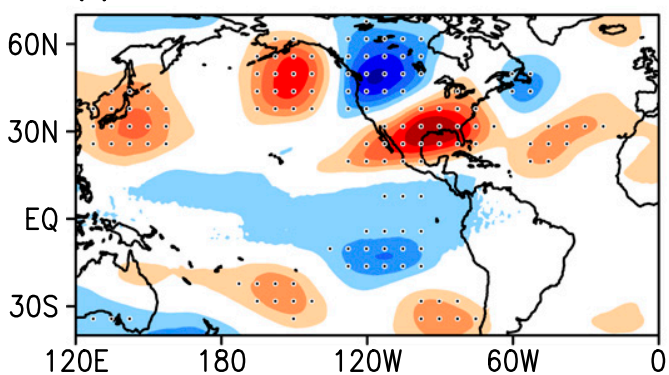

(b) JAS SLP and JAS GPLLJ

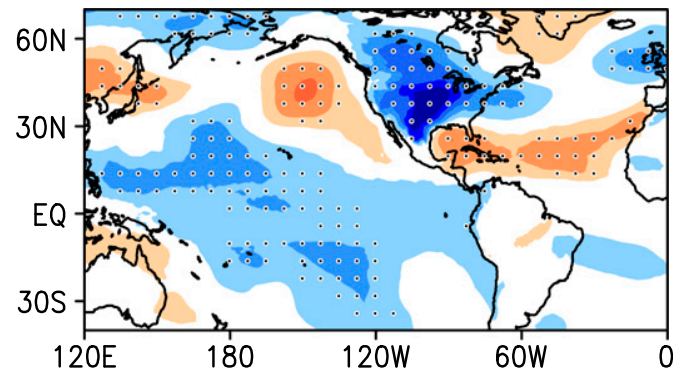

(d) JAS U925 and JAS GPLLJ

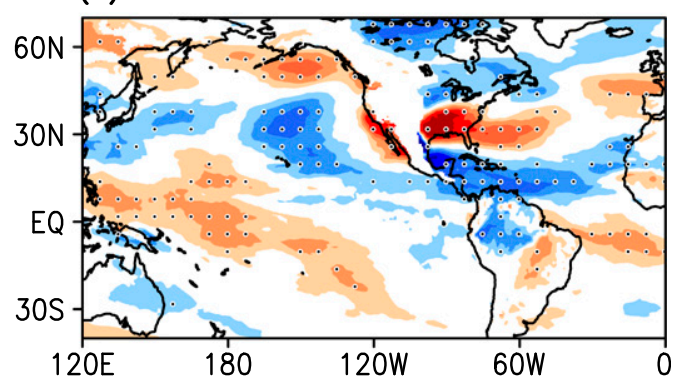

(f) JAS HGT500 and JAS GPLLJ

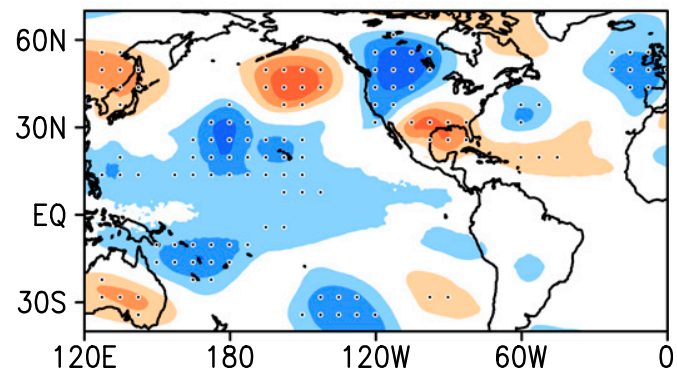

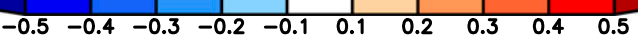

FIG. 15. As in Fig. 13, but for the FLOR-FA-no_ENSO run.

ENSO in order to accurately simulate the seasonal changes in the associated teleconnections.

We have presented a mechanistic hypothesis through which the relationship between the tropical Pacific SSTs and a stronger GPLLJ can differ in spring and summer. A schematic of the proposed mechanism is shown in Fig. 17. Winter La Niña conditions drive a SLP response in the IAS (correlation between the Niño-3.4 index and SLP index in the IAS is 0.4) during the following spring through changes in the Walker and Hadley circulations, which further intensify the easterlies in the Caribbean region (correlation between the SLP and CLLJ indices is 0.8). The correlation between the CLLJ and GPLLJ is 0.43 , suggesting that the easterlies in the Caribbean region (which correspond to a stronger CLLJ) are associated with the southerlies in the Great Plains (which correspond to a stronger GPLLJ.)

During summer (Fig. 17b), the SLP and SST gradients between the tropical Pacific (low pressure in the eastern tropical Pacific associated with El Niño) and Atlantic (high SLP along the coast of Florida) Oceans favor a stronger CLLJ (correlation between the SST gradient and CLLJ indices is 0.68), which in turn affects the strength of the southerlies over the Great Plains, yielding a stronger GPLLJ (correlation between the CLLJ and GPLLJ being 0.47). Thus, the summer link between the tropical Pacific SSTs and the GPLLJ is established through the tropical atmospheric circulation. As shown in Fig. 17b, the low SLP associated with 
Histogram of correlation between Niño3.4 and GPLLJ

(a) FLOR : AMJ

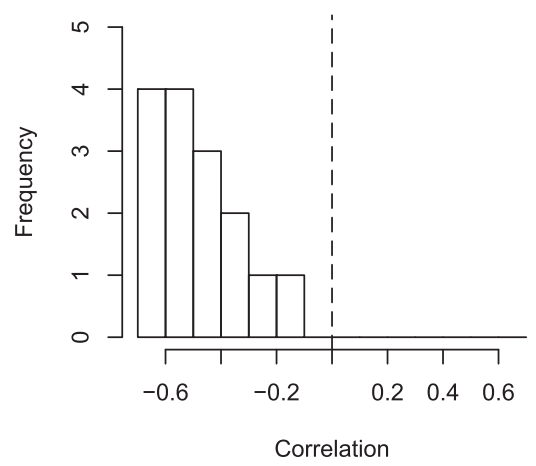

(c) FLOR-FA : AMJ

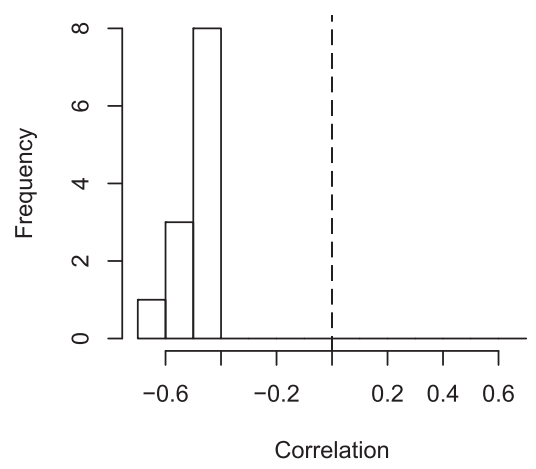

(b) FLOR : JAS

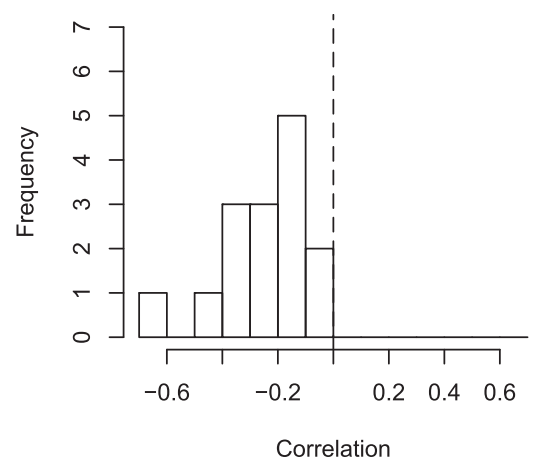

(d) FLOR-FA : JAS

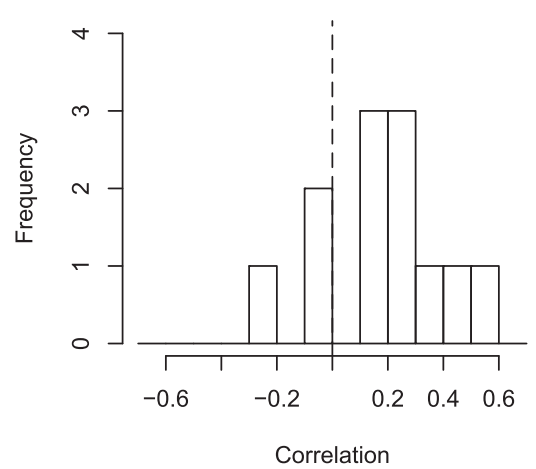

FIG. 16. Histogram of correlations between Niño-3.4 and GPLLJ indices for 40-yr chunks for FLOR in (a) AMJ and (b) JAS and for FLOR-FA in (c) AMJ and (d) JAS.

an El Niño in the tropical Pacific, together with the high SLP associated with the cold tropical Atlantic, provides the most favorable configuration for an El Niño to maintain a stronger GPLLJ through the abovesuggested mechanism. This is consistent with the previous observational and model studies, which noted that both the enhanced warm Pacific and cold Atlantic states contribute to maintain a stronger summer GPPLJ during summer (Whyte et al. 2008; Weaver et al. 2009). We further explored the hypothesized mechanism using the FLOR-FA run, and the model results were consistent with the proposed mechanism in observations.

In addition to the tropical link, we have also discussed the extratropical mechanism through which ENSO may affect the GPLLJ. The wave train emanating from the tropical western Pacific and extending into the North American region is suggested to affect the GPLLJ. By designing additional experiments where the ENSO variability was suppressed, we explored the variability in the IAS in the absence of ENSO. The relative roles of tropical and extratropical mechanisms in maintaining the atmospheric and oceanic anomalies in the IAS that are crucial for the GPLLJ-ENSO relation are discussed by comparing the FLOR-FA and FLOR-FA-no_ENSO runs. In spring, the effect of ENSO through the tropical and extratropical mechanisms is comparable, where, as in summer, the tropical link appears to play a dominant role. The quantitative comparison between the tropical and extratropical mechanisms in the GPLLJ-ENSO relation warrants further investigation.

We showed that correcting for SST biases in FLORFA and thus having more accurate phase locking of ENSO simulation yields a realistic seasonal change in the GPLLJ-ENSO relation. However, improvements in the tropical Pacific variability alone yielded correlations in summer that were weaker than in observations. This suggested that the extratropics (e.g., the North Pacific SSTs and the PNA) and the tropical-extratropical interactions play a role in determining the variability of the GPLLJ. The model experiment with no ENSO variability hints toward such an extratropical impact on the low-level jet over the Great Plains. 

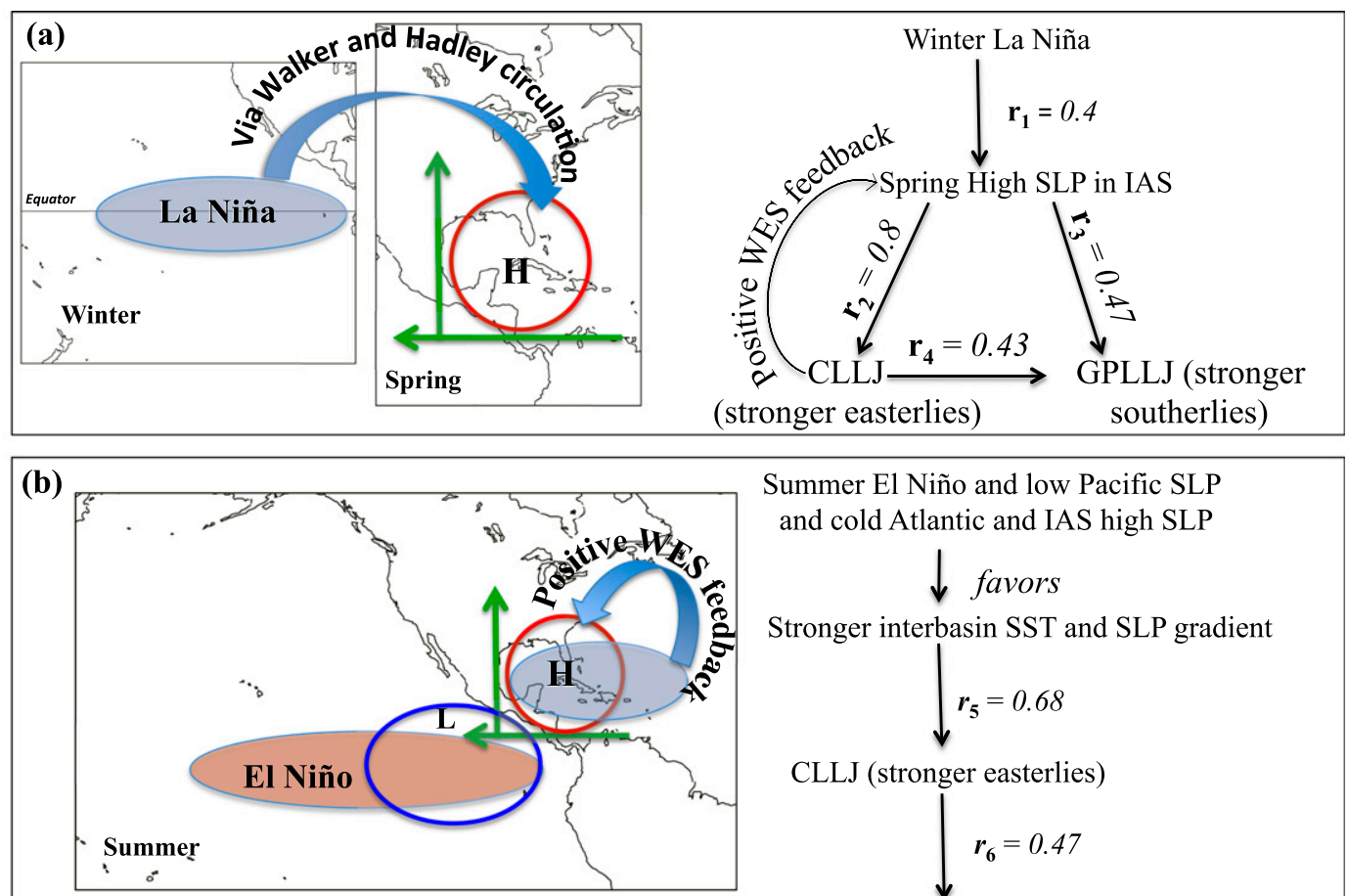

Summer El Niño and low Pacific SLP and cold Atlantic and IAS high SLP favors

Stronger interbasin SST and SLP gradient<smiles></smiles>

CLLJ (stronger easterlies)

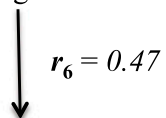

GPLLJ (stronger southerlies)

FIG. 17. Schematic of the mechanistic hypothesis to explain the GPLLJ-Pacific (a) spring and (b) summer teleconnection. In (a), $r_{1}$ indicates the correlation between winter Niño-3.4 and spring SLP $_{I}$ over IAS (SLP $_{I}$ is area-averaged SLP over the domain $\left.10^{\circ}-30^{\circ} \mathrm{N}, 80^{\circ}-65^{\circ} \mathrm{W}\right), r_{2}$ is the correlation between spring SLP $_{I}$ in the IAS and the CLLJ, $r_{3}$ is the correlation between spring $\mathrm{SLP}_{I}$ in the IAS and the GPLLJ, and $r_{4}$ is the correlation between the spring CLLJ and the GPLLJ. In (b), $r_{5}$ indicates the correlation between the CLLJ and the SST gradient between the tropical Pacific and Atlantic, and $r_{6}$ is the correlation between the summer CLLJ and the GPLLJ. All correlations are significant at 5\% significance level. In both the panels, the red and blue shaded (open) shapes represent warm (high) and cold (low) SSTs (SLP), respectively. The horizontal (vertical) green arrows represent zonal (meridional) winds suggesting enhancement of the CLLJ (GPLLJ). All the correlations are based on observed data.

While we focused primarily on the role of the tropical Pacific Ocean, several studies have also shown the importance of the North Pacific SSTs in driving the GPLLJ variability (Schubert et al. 2004; Hu and Huang 2009; Ting and Wang 1997; Munoz and Enfield 2011). Our results based on FLOR model suggest that the cold phase of PDO is associated with a stronger GPLLJ, which is in contrast to the observed teleconnection where a warm phase of PDO drives a stronger GPLLJ. Further work is evidently needed in order to clarify the role of the North Pacific extratropical response in the GPLLJ variability.

Acknowledgments. We thank Yohan Ruprich-Robert, Liping Zhang, and Vaishali Naik for helpful comments on the manuscript; Sarah Kapnick for suggestions on the schematic figure; and Seth Underwood for technical help with the model runs. We also thank the editor and anonymous reviewers for their constructive comments and suggestions. This work is supported by MAPP
Intra-Americas Sea proposal funded by NOAA Climate Program Office.

\section{REFERENCES}

Alexander, M., and J. Scott, 2002: The influence of ENSO on airsea interaction in the Atlantic. Geophys. Res. Lett., 29, doi:10.1029/2001GL014347.

Cook, K. H., E. K. Vizy, Z. S. Launer, and C. M. Patricola, 2008: Springtime intensification of the Great Plains low-level jet and Midwest precipitation in GCM simulations of the twenty-first century. J. Climate, 21, 6321-6340, doi:10.1175/2008JCLI2355.1.

Dee, D. P., and Coauthors, 2011: The ERA-Interim reanalysis: Configuration and performance of the data assimilation system. Quart. J. Roy. Meteor. Soc., 137, 553-597, doi:10.1002/qj.828.

Delworth, T. L., and Coauthors, 2006: GFDL's CM2 global coupled climate models. Part I: Formulation and simulation characteristics. J. Climate, 19, 643-674, doi:10.1175/JCLI3629.1.

— , and Coauthors, 2012: Simulated climate and climate change in the GFDL CM2.5 high-resolution coupled climate model. J. Climate, 25, 2755-2781, doi:10.1175/JCLI-D-11-00316.1.

Enfield, D. B., and D. A. Mayer, 1997: Tropical Atlantic sea surface temperature variability and its relation to El Niño-Southern 
Oscillation. J. Geophys. Res., 102, 929-945, doi:10.1029/ 96JC03296.

Giannini, A., Y. Kushnir, and M. A. Cane, 2000: Interannual variability of Caribbean rainfall, ENSO, and the Atlantic Ocean. J. Climate, 13, 297-311, doi:10.1175/1520-0442(2000)013<0297: IVOCRE $>2.0 . \mathrm{CO} ; 2$.

Horel, J. D., and J. M. Wallace, 1981: Planetary-scale atmospheric phenomena associated with the Southern Oscillation. Mon. Wea. Rev., 109, 813-829, doi:10.1175/1520-0493(1981)109<0813: PSAPAW $>2.0 . \mathrm{CO} ; 2$.

Hu, Z.-Z., and B. Huang, 2009: Interferential impact of ENSO and PDO on dry and wet conditions in the U.S. Great Plains. J. Climate, 22, 6047-6065, doi:10.1175/2009JCLI2798.1.

Jia, L., and Coauthors, 2015: Improved seasonal prediction of temperature and precipitation over land in a high-resolution GFDL climate model. J. Climate, 28, 2044-2064, doi:10.1175/ JCLI-D-14-00112.1.

Kalnay, E., and Coauthors, 1996: The NCEP/NCAR 40-Year Reanalysis Project. Bull. Amer. Meteor. Soc., 77, 437-471, doi:10.1175/1520-0477(1996)077,0437:TNYRP.2.0.CO;2.

Lee, S. K., R. Atlas, D. Enfield, C. Wang, and H. Liu, 2013: Is there an optimal ENSO pattern that enhances large-scale atmospheric processes conducive to tornado outbreaks in the United States? J. Climate, 26, 1626-1642, doi:10.1175/ JCLI-D-12-00128.1.

Munoz, E., and D. Enfield, 2011: The boreal spring variability of the Intra-Americas low-level jet and its relation with precipitation and tornadoes in the eastern United States. Climate Dyn., 36, 247-259, doi:10.1007/ s00382-009-0688-3.

Rayner, N. A., D. E. Parker, E. B. Horton, C. K. Folland, L. V. Alexander, D. P. Rowell, E. C. Kent, and A. Kaplan, 2003: Global analyses of sea surface temperature, sea ice, and night marine air temperature since the late nineteenth century. J. Geophys. Res., 108, 4407, doi:10.1029/2002JD002670.

Rienecker, M. M., and Coauthors, 2011: MERRA: NASA's Modern-Era Retrospective Analysis for Research and Applications. J. Climate, 24, 3624-3648, doi:10.1175/ JCLI-D-11-00015.1.

Saha, S., and Coauthors, 2010: The NCEP Climate Forecast System Reanalysis. Bull. Amer. Meteor. Soc., 91, 1015-1057, doi:10.1175/2010BAMS3001.1.

Schubert, S., M. J. Suarez, P. J. Pegion, R. D. Koster, and J. T. Bacmeister, 2004: Causes of long term drought in the U.S. Great Plains. J. Climate, 17, 485-503, doi:10.1175/ 1520-0442(2004)017<0485:COLDIT>2.0.CO;2.
Stensrud, D. J., 1996: Importance of low-level jets to climate: A review. J. Climate, 9, 1698-1711, doi:10.1175/1520-0442(1996) 009<1698:IOLLJT>2.0.CO;2.

Ting, M., and H. Wang, 1997: Summertime U.S. precipitation variability and its relation to Pacific sea surface temperature. J. Climate, 10, 1853-1873, doi:10.1175/1520-0442(1997)010<1853: SUSPVA $>2.0 . \mathrm{CO} ; 2$.

Vecchi, G. A., and Coauthors, 2014: On the seasonal forecasting of regional tropical cyclone activity. J. Climate, 27, 7994-8016, doi:10.1175/JCLI-D-14-00158.1.

von Storch, H., and F. W. Zwiers, 1999: Statistical Analysis in Climate Research. Cambridge University Press, 484 pp.

Wallace, J. M., and D. S. Gutzler, 1981: Teleconnections in the geopotential height field during the Northern Hemisphere winter. Mon. Wea. Rev., 109, 784-812, doi:10.1175/ 1520-0493(1981)109<0784:TITGHF > 2.0.CO;2.

Wang, C., 2005: ENSO, Atlantic climate variability, and the Walker and Hadley circulations. The Hadley Circulation: Past, Present, and Future, H. F. Diaz and R. S. Bradley, Eds., Kluwer Academic, 173-202.

, 2006: An overlooked feature of tropical climate: InterPacific-Atlantic variability. Geophys. Res. Lett., 33, L12702, doi:10.1029/2006GL026324.

_ 2007: Variability of the Caribbean low-level jet and its relations to climate. Climate Dyn., 29, 411-422, doi:10.1007/ s00382-007-0243-z.

Weaver, S. J., 2013: Factors associated with decadal variability in Great Plains summertime surface temperatures. J. Climate, 26, 343-350, doi:10.1175/JCLI-D-11-00713.1.

_ , and S. Nigam, 2008: Variability of the Great Plains low-level jet: Large-scale circulation context and hydroclimate impacts. J. Climate, 21, 1532-1551, doi:10.1175/2007JCLI1586.1.

- S. Schubert, and H. Wang, 2009: Warm season variations in the low-level circulation and precipitation over the central United States in observations, AMIP simulations, and idealized SST experiments. J. Climate, 22, 5401-5420, doi:10.1175/2009JCLI2984.1.

— S. Baxter, and A. Kumar, 2012: Climatic role of North American low-level jets on regional U.S. tornado activity. J. Climate, 25, 6666-6683, doi:10.1175/JCLI-D-11-00568.1.

Whyte, F., M. A. Taylor, T. Stephenson, and J. Campbell, 2008: Features of the Caribbean low level jet. Int. J. Climatol., 28, 119-128, doi:10.1002/joc.1510.

Yang, X., and Coauthors, 2015: Seasonal predictability of extratropical storm tracks in GFDL's high-resolution climate prediction model. J. Climate, 28, 3592-3611, doi:10.1175/JCLI-D-14-00517.1. 